 UNIVERSITY OF TECHNOLOGY
}

\section{Numerical investigation of collision dynamics of wet particles via force balance}

Citation for published version (APA):

Buck, B., Lunewski, J., Tang, Y., Deen, N. G., Kuipers, J. A. M., \& Heinrich, S. (2018). Numerical investigation of collision dynamics of wet particles via force balance. Chemical Engineering Research and Design, 132, 11431159. https://doi.org/10.1016/j.cherd.2018.02.026

DOI:

10.1016/j.cherd.2018.02.026

Document status and date:

Published: 01/04/2018

\section{Document Version:}

Typeset version in publisher's lay-out, without final page, issue and volume numbers

\section{Please check the document version of this publication:}

- A submitted manuscript is the version of the article upon submission and before peer-review. There can be important differences between the submitted version and the official published version of record. People interested in the research are advised to contact the author for the final version of the publication, or visit the $\mathrm{DOI}$ to the publisher's website.

- The final author version and the galley proof are versions of the publication after peer review.

- The final published version features the final layout of the paper including the volume, issue and page numbers.

Link to publication

\section{General rights}

Copyright and moral rights for the publications made accessible in the public portal are retained by the authors and/or other copyright owners and it is a condition of accessing publications that users recognise and abide by the legal requirements associated with these rights.

- Users may download and print one copy of any publication from the public portal for the purpose of private study or research.

- You may not further distribute the material or use it for any profit-making activity or commercial gain

- You may freely distribute the URL identifying the publication in the public portal.

If the publication is distributed under the terms of Article 25fa of the Dutch Copyright Act, indicated by the "Taverne" license above, please follow below link for the End User Agreement:

www.tue.nl/taverne

Take down policy

If you believe that this document breaches copyright please contact us at:

openaccess@tue.nl

providing details and we will investigate your claim. 


\title{
Numerical investigation of collision dynamics of wet particles via force balance
}

\author{
Britta Buck ${ }^{a, *}$, Johannes Lunewski ${ }^{a}$, Yali Tang ${ }^{b, c}$, Niels G. Deen ${ }^{c}$, \\ J.A.M. Kuipers ${ }^{b}$, Stefan Heinrich ${ }^{a}$ \\ a Institute of Solids Process Engineering and Particle Technology, Hamburg University of Technology, Denickestrasse \\ 15, 21073 Hamburg, Germany \\ ${ }^{\mathrm{b}}$ Multiphase Reactors Group, Department of Chemical Engineering and Chemistry, Eindhoven University of \\ Technology, P.O. Box 513, 5600 MB Eindhoven, The Netherlands \\ ${ }^{c}$ Multiphase \& Reactive Flows Group, Department of Mechanical Engineering, Eindhoven University of Technology, \\ P.O. Box 513, 5600 MB Eindhoven, The Netherlands
}

\section{A R T I C L E I N F O}

\section{Article history:}

Received 1 September 2017

Received in revised form 15 January

2018

Accepted 16 February 2018

Available online xxx

Keywords:

Coefficient of restitution

Force balance

Collision

Liquid layer

Numerical model

\begin{abstract}
A B S T R A C T
Knowledge of collision dynamics of solid materials is fundamental to understand and predict the behavior of particulate macro processes such as in fluidized beds, mixers and granulators. Especially, particle collisions with the presence of liquids are still not fully understood. Many experimental investigations address energy dissipation due to the collision and the liquid involved. For this the so-called coefficient of restitution is often used, which is defined as ratio of rebound to impact velocity, as such describing dissipation of kinetic energy. In this work a numerical model based on force balances is proposed, which predicts the coefficient of restitution for normal and oblique collisions of a particle and a wet plate. The model is validated by extensive experiments regarding the influence of collision parameters such as collision velocity and angle, liquid properties as well as initial particle rotation. Good agreement between model and experiments is found for all investigated parameters.
\end{abstract}

(๖ 2018 Institution of Chemical Engineers. Published by Elsevier B.V. All rights reserved.

\section{Introduction}

Collision dynamics of particles and between particles and walls are fundamental knowledge for understanding the overall dynamic behavior of particulate processes, such as in fluidized beds or mixers. If liquids are additionally involved in the process as liquid layers or droplets on the particle, e.g. in granulation or agglomeration, or as moisture in drying applications, the collision dynamics become even more complex. The particles may stick together after collision forming an agglomerate, or they might rebound resulting in a distribution of the liquid between the particles. Consequently, this leads to much higher complexity also for understanding or modeling of wet particulate processes.
To characterize collision dynamics many authors, e.g. Luding (1998), Davis et al. (2002), Antonyuk et al. (2009), Hogekamp et al. (1994) and Gollwitzer et al. (2012), use the socalled coefficient of restitution (CoR), which is defined as ratio of the relative rebound velocity of the particle to the relative impact velocity:

$e=\left|\frac{v_{\mathrm{R}}}{v}\right|=\sqrt{\frac{E_{\text {kin }, \mathrm{R}}}{E_{\text {kin }}}}=\sqrt{1-\frac{E_{\text {diss }}}{E_{\text {kin }}}}$

Thus, the coefficient of restitution describes the energy dissipated during a collision. In industrial processes particle collisions can occur normally (perpendicular) but also obliquely, in which case the CoR can be divided into normal, tangential and rotational components:

$e_{\mathrm{n}}=\left|\frac{v_{\mathrm{R}, \mathrm{n}}}{v_{\mathrm{n}}}\right|$

E-mail address: britta.buck@tuhh.de (B. Buck). https://doi.org/10.1016/j.cherd.2018.02.026

0263-8762/@ 2018 Institution of Chemical Engineers. Published by Elsevier B.V. All rights reserved. 


\section{Nomenclature}

$\alpha \quad$ collision angle $\left[{ }^{\circ}\right]$

$\alpha_{\mathrm{d}} \quad$ empirical constant [-]

$\delta_{1} \quad$ layer thickness [m]

$\delta_{\mathrm{n}} \quad$ normal displacement $[\mathrm{m}]$

$\varepsilon \quad$ surface roughness [m]

$\eta \quad$ viscosity [Pa s]

$\varphi \quad$ half-filling angle [ $\left.{ }^{\circ}\right]$

$\mu_{\mathrm{sl}} \quad$ sliding friction coefficient [-]

$v_{\mathrm{i}} \quad$ Poisson ratio [-]

$\omega \quad$ rotational velocity [ $\mathrm{rad} \mathrm{s}^{-1}$ ]

$\rho$ density $\left[\mathrm{kg} \mathrm{m}^{-3}\right]$

$\sigma \quad$ surface tension $\left[\mathrm{N} \mathrm{m}^{-1}\right]$

$\theta \quad$ liquid contact angle $\left[{ }^{\circ}\right]$

A, B, C non-dimensional coefficients [-]

$a^{*} \quad$ non-dimensional distance [-]

Ca capillary number [-]

$E^{*} \quad$ Young's elastic modulus $\left[\mathrm{N} \mathrm{m}^{-2}\right]$

$E_{\text {kin }} \quad$ kinetic energy [J]

$E_{\text {diss }}$ dissipative energy [J]

$e^{\text {coefficient of restitution [-] }}$

$F_{\mathrm{C}} \quad$ contact force $[\mathrm{N}]$

$F_{\mathrm{c}, \mathrm{d}} \quad$ damping contact force $[\mathrm{N}]$

$F_{\mathrm{c}, \mathrm{el}} \quad$ elastic contact force $[\mathrm{N}]$

$F_{\text {cap }} \quad$ capillary force [N]

$F_{\text {cap }, \sigma} \quad$ surface tension force $[N]$

$F_{\text {cap,p }}$ capillary pressure force $[\mathrm{N}]$

$F_{g} \quad$ gravitational force $[\mathrm{N}]$

$F_{\text {vis }} \quad$ viscous force $[\mathrm{N}]$

$F_{\text {vis }, \infty} \quad$ viscous drag force $[\mathrm{N}]$

$F_{\text {vis,wall viscous wall force }[\mathrm{N}]}$

$G^{*}$ shear modulus [Pa]

$I_{P} \quad$ moment of inertia $\left[\mathrm{kg} \mathrm{m}^{2}\right]$

$k_{\mathrm{d}} \quad$ damping constant $\left[\mathrm{N} \mathrm{s} \mathrm{m}^{-1}\right]$

$k_{\mathrm{el}} \quad$ elastic spring constant $\left[\mathrm{N} \mathrm{m}^{-3 / 2}\right]$

m mass [kg]

$M_{\text {vis }} \quad$ viscous moment $[\mathrm{Nm}]$

$p_{\mathrm{c}} \quad$ capillary pressure $[\mathrm{Pa}]$

Re Reynolds number [-]

$R_{\mathrm{P}} \quad$ particle radius [m]

$r_{\mathrm{a}} \quad$ azimuthal radius $[\mathrm{m}]$

$r_{\mathrm{m}} \quad$ meridional radius [m]

$r_{c} \quad$ contact radius between liquid and particle [m]

$\mathrm{V}_{\mathrm{b}} \quad$ bridge volume $\left[\mathrm{m}^{3}\right]$

$v \quad$ velocity $\left[\mathrm{m} \mathrm{s}^{-1}\right]$

$v_{c} \quad$ tangential velocity in the contact point $\left[\mathrm{m} \mathrm{s}^{-1}\right]$

$y \quad$ distance from $y$-axis $[\mathrm{m}]$

Indices

$\mathrm{n}$ normal

$\mathrm{R} \quad$ rebound

$\mathrm{t}$ tangential

$\omega \quad$ rotational

$e_{t}=\frac{v_{R, t}}{v_{t}}$

$e_{\omega}=\frac{\omega_{\mathrm{R}}}{\omega}$

Additionally, initial and post-collision rotation, $\omega$ and $\omega_{\mathrm{R}}$ respectively, can be analyzed separately.
Dry particle-particle as well as particle-wall collisions were already extensively investigated by several authors. Experimental investigations were for example conducted by Kharaz et al. (2001), Dong and Moys (2006), Antonyuk et al. (2010) and Foerster et al. (1994). For different materials the normal coefficient of restitution was either found to be independent of impact velocity for elastic materials or to decrease with increasing impact velocity for (partly) plastic deforming materials. For oblique collisions tangential movement depends on the material properties of the colliding surfaces. The particles might roll/stick or slide on the wall depending on the friction coefficient of the surfaces and on collision angle Foerster et al. (1994). Furthermore, Dong and Moys (2006) found a strong dependence of the tangential coefficient of restitution on initial rotation of the particles.

Various contact models were developed to predict the rebound behavior of different materials. A linear model for normal contact forces during elastic contacts was developed by Hertz (1882), which was extended to oblique collisions by Mindlin and Deresiewicz (1953). Tsuji et al. (1992) further extended the models of Hertz and Mindlin \& Deresiewicz to non-linear visco-elastic collisions by applying a damping force to the elastic contact forces. The models of Hertz as well as Tsuji et al. both feature a constant normal CoR in dependence of collision velocity. Brilliantov et al. (1996), as an example, developed a model also based on Hertz, which includes dissipative viscoelastic effects resulting in a velocity dependent normal CoR. Thornton (2009) developed alternative models for elastic materials having a closer look on the influence of initial rotation as well as for particles with inelastic deformation behavior (Thornton et al., 2013). The influence of adhesion on micro-particles was included into models for example by Liu et al. (2011). Kruggel-Emden et al. (2007) summarized various dry normal force models (linear, non-linear, hysteretic) in a review and further extended the models. Di Renzo and Di Maio (2004) compared normal and tangential contact force models for their applicability in discrete element method (DEM) simulations.

Deformation behavior of dry particles during collisions were further investigated via finite element (FEM) simulations by Wu et al. (2003b, 2003a, 2009) and Zheng et al. (2012). Feng et al. (2009) modeled the adhesion of micro-particles.

Knowledge about dry contact forces is the basis for understanding wet particle collisions. However, the liquid introduces additional forces such as viscous and capillary forces, which lead to the complex behavior of wet particulate processes. Therefore, extensive research regarding the influence of the liquid on collisions dynamics is also necessary.

Several authors considered particle-wall or particle-particle collisions immersed in liquid in normal direction (Joseph et al., 2001; Davis et al., 1986) as well as for oblique impacts (e.g. Joseph and Hunt (2004) as well as Yang and Hunt (2006)). They found the normal coefficient of restitution to be strongly reduced due to viscous forces in the liquid and a dependence on the Stokes number $S t=\frac{m_{\mathrm{P}} v_{\mathrm{n}}}{6 \pi \eta R_{\mathrm{P}}^{2}}$ was described. For oblique collisions the tangential movement was found to differ if the surfaces are either very smooth and some liquid is present between the surface during the complete collision, or if a solid-solid contact happens due to surface roughness. For rough surfaces the interactions of immersed particles in tangential direction nearly equal those of dry collisions, while for smooth surface friction is strongly 
reduced by up to one order of magnitude (Joseph and Hunt, 2004).

Considerable work was also done in experimental investigations of particles colliding with walls covered by thin liquid layers, e.g. in normal direction by Barnocky and Davis (1988), Hogekamp et al. (1994), Davis et al. (2002), Kantak et al. (2005), Antonyuk et al. (2009), Sutkar et al. (2015), Gollwitzer et al. (2012), Fu et al. (2004) as well as in Crüger et al. (2016a). Wet oblique collision experiments with thin liquid layers were exemplary conducted by Kantak and Davis (2004), Ma et al. (2013, 2015, 2016), Crüger et al. (2016b), Buck et al. (2017). In comparison to collisions immersed in liquid, in the case of thin layers the layer thickness has additionally to be taken into account. Furthermore, capillary forces may not be negligible, since a liquid bridge forms between liquid layer and rebounding particles, rupturing at a critical length.

Besides experiments, volume of fluid (VOF) combined with immersed boundary (IB) methods are used for simulating wet particle collisions to further investigate collision dynamics, especially for configurations, which are difficult to realize experimentally (very thin layers, small velocities). Lin and Lin (2013) for example performed immersed boundary simulations investigating the flow field of a particle moving normally in the direction of a wall. Jain et al. (2012) combined VOF and IB methods to model a particle impacting normally with a plate, which is covered by a liquid layer. The results of CoR agree well with experiments, however the formation of the liquid bridge did not. Hence, Tang et al. (2017) extended this VOF/IB model by further implementing a tensile force model and a contact model. This led to a much better agreement between model and experiments regarding the overall collision dynamics including liquid bridge shape and lifetime as well as the dependence of the CoR on several parameters (collision velocity, layer thickness, liquid viscosity, surface tension). Kan et al. (2015) used a computational fluid dynamics approach to investigate the effect of collision velocity on the capillary bridge force as well as the influence of particle wettability on collision dynamics during normal particle-particle collisions (Kan et al., 2016). Wu et al. (2016) used direct numerical simulation (DNS) to predict liquid bridge formation between wet particles and liquid transport during collision of particles (Wu et al., 2017).

Several other authors worked on a description of collision dynamics for wet particle collisions based on force or energy balances. Ennis et al. (1991) proposed a limiting criteria for sticking of two particles due to viscous effects characterized by a critical stokes number. Capillary forces are neglected though, while the solid-solid contact is accounted for by a given "dry CoR". Darabi et al. (2009) used a similar approach as Ennis et al. predicting normal, limiting cases for collisions, where capillary forces or viscous forces are dominating. Antonyuk et al. (2009) proposed a force balance model including contact forces, drag, capillary and viscous forces to predict the rebound behavior of a particle normally colliding with a wet target plate. Also Müller and Huang (2016) developed an energy balance including viscous effects for normal wet particle-wall collisions. Mikami et al. (1998) implemented contact forces, drag as well as capillary forces into a DEM simulation to simulate a wet fluidization process. Also Nase et al. (2001) proposed a DEM model for wet granular systems including viscous and capillary forces and validated the model by comparing simulation and experiment of the static angle of repose as well as tumbler experiments.
However, no force balance model for normal and especially oblique wet particle-wall or particle-particle collisions exist in literature yet, which is fully validated by extensive single particle collision experiments. Therefore, this work proposes a force balance model that predicts normal and oblique collision dynamics of particles and walls covered by a liquid layer. Contact forces and gravitational force are considered as well as viscous and capillary forces to represent the dissipation of energy in the liquid layer. Previous experimental results of our group Crüger et al. (2016a), Crüger et al. (2016b) and Buck et al. (2017) are used to validate the force balance model for a large range of parameters.

\section{Methodology}

\subsection{Force balance model}

A force balance is used for simulating collision dynamics for a particle impacting a wet plate in this work. For this the normal part of a collision is divided into four subsections (Fig. 1) as can also be found in Antonyuk et al. (2009) or Sutkar et al. (2015). First the particle penetrates into the liquid layer resulting in viscous $F_{\text {vis,n }}$ and capillary forces $F_{\text {cap,n }}$ acting on the particle. When reaching the solid surface or the wall elastic and dissipative contact forces $F_{c, n}$ lead to a rebound of the particle changing the direction of motion. The wall is assumed to have an infinite mass compared to the particle and thus gains no movement. During the third phase the particle emerges back to the surface of the liquid again accompanied by viscous and capillary forces. When emerging from the surface of the liquid a liquid bridge is formed, which stretches until a critical rupture length of the bridge is reached and the bridge ruptures. During this phase still viscous and capillary forces act. After rupture a part of the liquid stays on the lower part of the particle, while the remaining fraction falls back into the liquid layer. Furthermore, throughout all phases a gravitational force $F_{g, n}$ acts on the particle.

For modeling an oblique collision a superposition of normal and tangential movement is assumed, except for the tangential contact force (phase II), which depends on the deformation in normal direction. Thus, the motion in normal direction is modeled as described above, while in tangential direction during phase II an additional contact force in tangential direction is added $\left(F_{c, t}\right)$, which includes Coulomb's friction law as limiting factor, and in phase I and III a tangential viscous force $\left(F_{\text {vis,t }}\right)$ and viscous momentum $\left(M_{\text {vis }}\right)$ are included. Fig. 2 shows schematically the acting forces during phase III and IV of an oblique collision.

The particle's movement with time is calculated by solving Newton's law of motion in Matlab for all phases of the collision via using the function ode45:

$m_{\mathrm{P}} \frac{\mathrm{d} v_{\mathrm{n}}}{\mathrm{dt}}=\sum F_{\mathrm{n}}$

$m_{\mathrm{P}} \frac{\mathrm{d} v_{\mathrm{t}}}{\mathrm{dt}}=\sum F_{\mathrm{t}}$

$I_{P} \frac{d \omega}{d t}=F_{c, t} R_{P}+M_{\text {vis }}$

Contact forces acting during a contact between two solid surfaces can be calculated by the model of Tsuji et al. (1992), which is based on the models of Hertz (1882) and Mindlin and Deresiewicz (1953). The contact force consist of one elastic part 


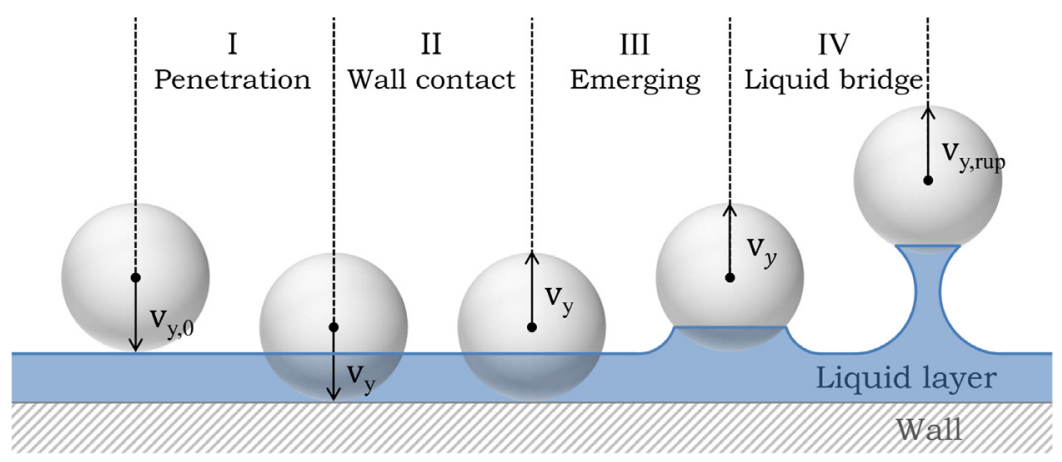

Fig. 1 - Schematic of collision subsections: (phase I) penetration of particle into liquid; (phase II) contact of solid surfaces; (phase III) particle emerging from liquid; (phase IV) formation and rupture of liquid bridge.
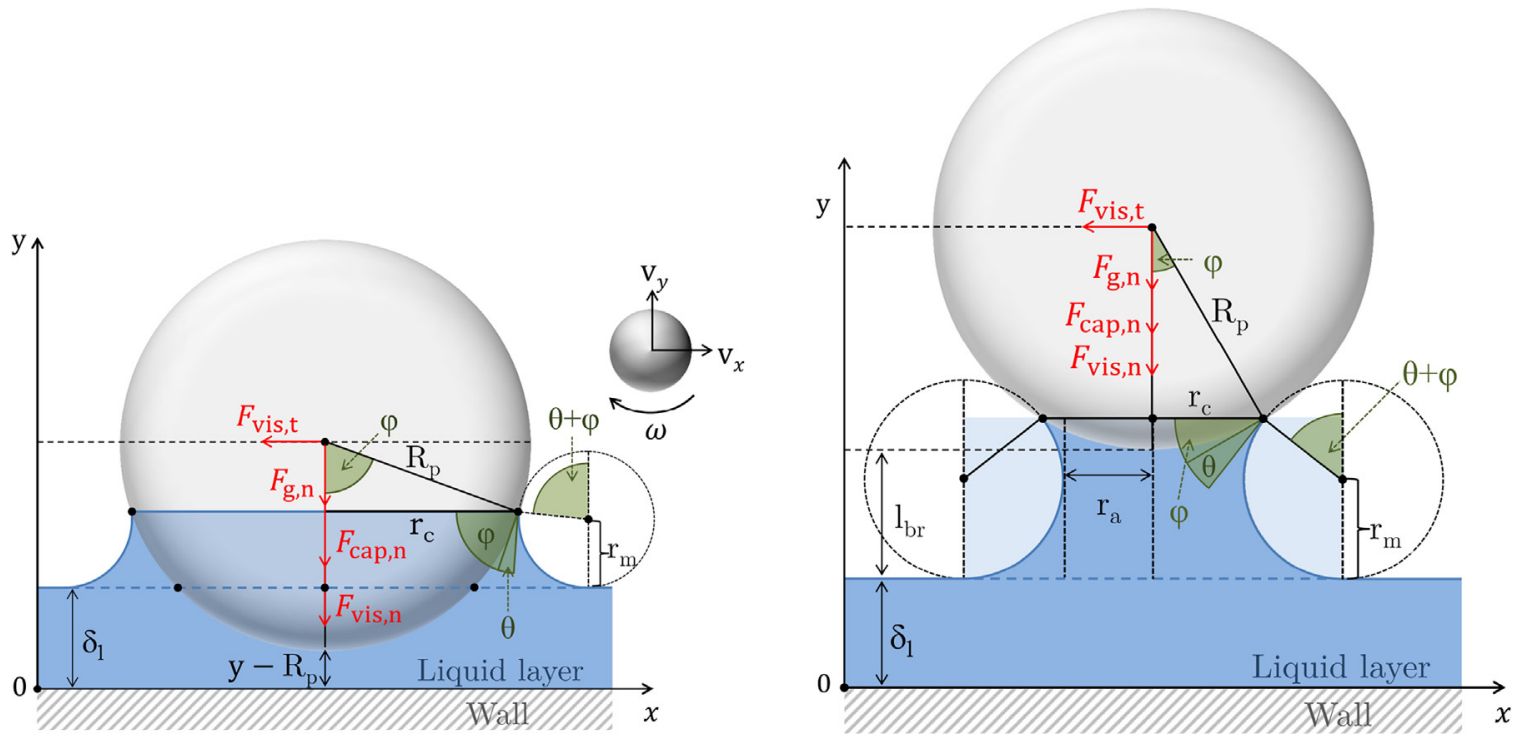

Fig. 2 - Schematic representation of the model assumptions in phase III and IV.

$F_{c, e l}$ and one dissipative part $F_{c, d}$. In normal direction it can be expressed as:

$F_{\mathrm{c}, \mathrm{n}}=F_{\mathrm{c}, \mathrm{el}, \mathrm{n}}+F_{\mathrm{c}, \mathrm{d}, \mathrm{n}}$

$=k_{\mathrm{el}, \mathrm{n}} \cdot \delta_{\mathrm{n}}^{3 / 2}+k_{\mathrm{d}, \mathrm{n}} \cdot v_{\mathrm{n}}$

with $\delta_{\mathrm{n}}$ representing the displacement in normal direction. With the assumption of the plate not getting deformed and being static, the normal displacement can be calculated from particle radius $R_{P}$ and the position of the particle in $y$-direction:

$\delta_{\mathrm{n}}=R_{\mathrm{P}}-\mathrm{y}$

$k_{\mathrm{el,n}}$ and $k_{\mathrm{d}, \mathrm{n}}$ are the elastic spring rate and damping coefficient, respectively:

$k_{\mathrm{el}, \mathrm{n}}=\frac{4}{3} \quad E^{*} \sqrt{R^{*}}$

$k_{\mathrm{d}, \mathrm{n}}=\alpha_{\mathrm{d}} \quad \sqrt{m^{*} \cdot k_{\mathrm{el} . \mathrm{n}}} \delta_{\mathrm{n}}^{1 / 4}$

The star * indicates averaged properties of both collision partners regarding mass $m^{*}$, radius in the contact area $R^{*}$ and elastic modulus $E^{*} . \alpha_{\mathrm{d}}$ is a damping constant depending on the dry coefficient of restitution in normal direction $e_{\mathrm{n}, \mathrm{dry}}$ :

$m^{*}=\left(\frac{1}{m_{i}}+\frac{1}{m_{j}}\right)^{-1}$

$R^{*}=\left(\frac{1}{R_{i}}+\frac{1}{R_{j}}\right)^{-1}$

$E^{*}=\left(\frac{1-v_{i}^{2}}{E_{i}}+\frac{1-v_{j}^{2}}{E_{j}}\right)^{-1}$

$\alpha_{\mathrm{d}}=-\ln \left(e_{\mathrm{n}, \mathrm{dry}}\right) \cdot \sqrt{\frac{5}{\ln ^{2}\left(e_{\mathrm{n}, \mathrm{dry}}\right)+\pi^{2}}}$

The contact force in tangential direction is similar defined as that in normal direction:

$F_{\mathrm{c}, \mathrm{t}}=F_{\mathrm{c}, \mathrm{el}, \mathrm{t}}+F_{\mathrm{c}, \mathrm{d}, \mathrm{t}}$

$=k_{\mathrm{el}, \mathrm{t}} \cdot \delta_{\mathrm{t}}+k_{\mathrm{d}, \mathrm{t}} \cdot v_{\mathrm{t}}$

with elastic stiffness

$k_{\mathrm{el}, \mathrm{t}}=8 \cdot G^{*} \sqrt{R^{*}} \cdot \delta_{\mathrm{n}}^{1 / 2}$ 
Tsuji et al. (1992) propose that the tangential damping coefficient can be assumed to equal that of the normal direction:

$k_{\mathrm{d}, \mathrm{t}}=k_{\mathrm{d}, \mathrm{n}}=\alpha_{\mathrm{d}} \cdot \sqrt{m^{*} \cdot k_{\mathrm{el}, \mathrm{n}}} \cdot \delta_{\mathrm{n}}^{1 / 4}$

wherein $G^{*}$ is the average shear modulus composed of the shear modulus of both colliding materials $G_{i}$ :

$G_{i}=\left(\frac{E_{i}}{2 \cdot\left(1+v_{i}\right)}\right)$

$G^{*}=\left(\frac{2-v_{i}^{2}}{G_{i}}+\frac{2-v_{j}^{2}}{G_{j}}\right)^{-1}$

The tangential displacement $\delta_{\mathrm{t}}$ accounts for the tangential movement of the particle in the contact point including rotation of the particle and is calculated according to Di Renzo and Di Maio (2004):

$\delta_{\mathrm{t}}=\left(x-x_{0}\right)+\phi_{\mathrm{rot}} \cdot R_{P}$

with $x_{0}$ as the $x$-coordinate of the particle center, when particle and wall are touching the first time, and $\phi_{\text {rot }}$ the angle of rotation.

The tangential contact force however is limited by Coulomb's friction law. When the tangential contact force reaches the product of sliding friction coefficient $\mu_{\mathrm{sl}}$ and normal contact force, sliding occurs:

$F_{\mathrm{c}, \mathrm{t}}= \begin{cases}F_{\mathrm{c}, \mathrm{el}, \mathrm{t}}+F_{\mathrm{c}, \mathrm{d}, \mathrm{t}} & \text { if } F_{\mathrm{c}, \mathrm{t}}<\mu_{\mathrm{sl}} \cdot F_{\mathrm{c}, \mathrm{n}} \\ \mu_{\mathrm{sl}} \cdot F_{\mathrm{c}, \mathrm{n}} & \text { if } F_{\mathrm{c}, \mathrm{t}} \geq \mu_{\mathrm{sl}} \cdot F_{\mathrm{c}, \mathrm{n}}\end{cases}$

Viscous (or drag) forces account for the resistance due to the liquid shear flow, which results from the moving particle displacing the liquid. They are investigated by many researchers, e.g. Shi and McCarthy (2008), Lin and Lin (2013) and Pitois et al. (2000). White (2006) propose a model for a particle moving in an infinite liquid, which is valid in a wide range of Reynolds number $R e<2 \times 10^{5}$. Applying a particle Reynolds number (Eq. (26)), where the characteristic length is defined as diameter of the particle fraction, which is submerged in a liquid layer on a plate, this model was approximated for the case of a particle impacting a wet plate:

$F_{\mathrm{vis}, \mathrm{n}, \infty}=6 \pi \eta_{1} R_{\mathrm{P}} \sin (\varphi) u_{\mathrm{n}} \cdot\left(1+\frac{R e_{\mathrm{P}}}{4 \cdot\left(1+\sqrt{R e_{\mathrm{P}}}\right)}+\frac{R e_{\mathrm{P}}}{60}\right)$

$\operatorname{Re}_{\mathrm{P}}=\frac{2 R_{\mathrm{P}} \sin (\varphi) v_{\mathrm{n}} \rho_{\mathrm{l}}}{\eta_{1}}$

with $\varphi$ as the so-called half-filling angle, characterizing the fraction of the particle, which is covered by liquid.

For a particle approaching close to a wall several authors (Chan and Horn, 1985; Matthewson, 1988; Lian et al., 2001) propose a different equation depending on the distance between both solid surfaces:

$F_{\text {vis, }, \text { wall }}=\frac{6 \pi \eta_{1} R_{\mathrm{P}}^{2} v_{\mathrm{n}}}{\delta_{1}-\mathrm{y}}$

Since this equation tends to infinity for the gap size approaches zero, a critical minimum gap size $\delta_{1}-y=0.5 \mu \mathrm{m}$ was defined according to an average roughness of the particles. After reaching this critical gap size the viscous force is kept constant until contact of particle and wall.

In this model a combination of both models for the normal viscous force is used, where always the larger of both is acting:

$F_{\text {vis }, \mathrm{n}}= \begin{cases}F_{\mathrm{vis}, \mathrm{n}, \infty} & \text { if } F_{\text {vis,n,wall }} \leq F_{\mathrm{vis}, \mathrm{n}, \infty} \\ F_{\text {vis }, \mathrm{n}, \text { wall }} & \text { if } F_{\text {vis,n,wall }}>F_{\text {vis }, \mathrm{n}, \infty}\end{cases}$

In tangential direction a viscous lubrication force and a viscous momentum are implemented, which were first introduced by Goldman et al. (1967). These model equations consider the force and momentum in the gap between a particle moving parallel to a wall inside a liquid.

$$
\begin{aligned}
F_{\text {vis }, t}= & 6 \pi \eta R_{\mathrm{P}} \\
& \cdot\left(\left(\frac{8}{15} \ln \left(\frac{R_{\mathrm{P}}}{\delta_{l}-y}\right)+0.9588\right) v_{\mathrm{t}}\right. \\
& \left.+\left(\frac{2}{15} \ln \left(\frac{R_{\mathrm{P}}}{\delta_{l}-y}\right)+0.2526\right) \omega R_{\mathrm{P}}\right) \\
\mathrm{M}_{\text {vis }}= & 8 \pi \eta R_{\mathrm{P}}^{2} \\
& \cdot\left(\left(\frac{1}{10} \ln \left(\frac{R_{\mathrm{P}}}{\delta_{l}-y}\right)+0.1895\right) v_{\mathrm{t}}\right. \\
& \left.+\left(\frac{2}{5} \ln \left(\frac{R_{\mathrm{P}}}{\delta_{l}-y}\right)+0.3817\right) \omega R_{\mathrm{P}}\right)
\end{aligned}
$$

Capillary forces are modeled only in normal direction and in accordance to the toroid approximation by Kralchevsky and Nagayama (2001). They are composed of two parts, one part resulting from the surface tension $F_{c a p, \sigma}$ and the other from capillary pressure $F_{\text {cap,p: }}$ :

$F_{\text {cap }, \mathrm{n}}=F_{\text {cap }, \sigma}+F_{\text {cap }, p}$

$=-2 \pi \sigma r_{\mathrm{c}} \sin (\varphi+\theta)+\pi r_{\mathrm{c}}^{2} p_{\mathrm{c}}$

with the liquid contact angle $\theta$. Here $r_{\mathrm{c}}$ represents the radius of that part of the particle, which is in contact with the liquid as indicated in Fig. 2. The capillary pressure $p_{c}$ depends on surface tension as well as the meridional radius $r_{\mathrm{m}}$ and the azimuthal radius $r_{\mathrm{a}}$, which represents the smallest cross sectional radius of the liquid bridge:

$p_{\mathrm{c}}=\sigma \cdot\left(\frac{1}{r_{\mathrm{m}}}-\frac{1}{r_{\mathrm{a}}}\right)$

$r_{a}= \begin{cases}r_{\mathrm{c}}+r_{\mathrm{m}} \cdot[\sin (\varphi+\theta)-1] & \text { if } \varphi+\theta<90^{\circ} \\ r_{\mathrm{c}} & \text { if } \varphi+\theta \geq 90^{\circ}\end{cases}$

$r_{\mathrm{m}}=\frac{\mathrm{y}-\mathrm{R}_{\mathrm{P}} \cdot \cos \varphi-\delta_{\mathrm{l}}}{1+\cos (\varphi+\theta)}$

The liquid bridge breaks after reaching a certain length $l_{\text {rupt }}$ ending phase IV as well as the calculation of the force balance. The maximum rupture length is calculated via the equation of Pitois et al. (2001) depending on capillary number $\mathrm{Ca}$, liquid contact angle $\theta$ and the volume of the bridge $\mathrm{V}_{\mathrm{b}}$ :

$l_{\text {rupt }}=\left(1+\frac{\theta}{2}\right) \cdot\left(1+C a^{1 / 2}\right) \cdot V_{b}^{1 / 3}$

$\mathrm{Ca}=\frac{v_{\mathrm{n}} \eta}{\sigma}$ 


\begin{tabular}{|c|c|c|c|c|c|}
\hline Material & Diameter $[\mathrm{mm}]$ & Density $\left[\mathrm{kg} \mathrm{m}^{-3}\right]$ & E-modulus [GPa] & Poisson ratio $[-]$ & Dry CoR $[-]$ \\
\hline Glass (SWARCO-Vestglas, 2018a,b) & $\begin{array}{l}0.91 \\
1.74\end{array}$ & 2500 & 63.0 & 0.23 & 0.96 \\
\hline$\gamma-\mathrm{Al}_{2} \mathrm{O}_{3}$ (Antonyuk et al., 2009) & 1.74 & 1040 & 14.5 & 0.25 & 0.76 \\
\hline
\end{tabular}

Table 2 - Liquid properties at $20^{\circ} \mathrm{C}$.

\begin{tabular}{llll} 
Liquid & Density $\left[\mathrm{kg} \mathrm{m}^{-3}\right]$ & Viscosity $[\mathrm{mPa}]$ & Surface tension $\left[\mathrm{mN} \mathrm{m}{ }^{-1}\right]$ \\
\hline Water & 998 & 1.0 & 72.80 \\
$60 \mathrm{gL}^{-1}$ Tween 20 & 998 & 1.0 & 37.30 \\
35 wt\% glycerol (Glycerine Producers' Association, 1963) & 1086 & 3.0 & 69.61 \\
51 wt\% glycerol (Glycerine Producers' Association, 1963) & 1130 & 6.7 & 68.20 \\
\hline
\end{tabular}

A detailed description of the calculation of the bridge volume can be found in Appendix A.

For gravitational force the mass of the particle and the added mass by the liquid bridge is considered:

$F_{\mathrm{g}, \mathrm{n}}=\left(\frac{4}{3} \pi R_{\mathrm{P}}^{3} \rho_{\mathrm{s}}+\mathrm{V}_{\mathrm{b}} \rho_{\mathrm{l}}\right) \cdot g$

The buoyancy force was found to be neglectable and was therefore not integrated into the model.

\subsection{Experimental validation}

For experimental validation mainly results of our previous works (Crüger et al., 2016a; Crüger et al., 2016b; Buck et al., 2017) were used. Additionally, some new experiments were conducted.

\subsubsection{Experimental setup}

The setup used for conducting experiments for validation mainly consists of a particle impacting on a wet target plate. The particle either falls down onto the plate by gravity (Crüger et al., 2016a), shot obliquely onto the plate by pressurized air (Crüger et al., 2016b) or rolls down a ramp colliding with the plate having initial particle rotation (Buck et al., 2017). The plate is either dry or covered with a liquid layer of defined thickness. The layer thickness is controlled before each collision by a confocal sensor. The collision is captured from two directions by synchronized high-speed cameras allowing a three-dimensional analysis of the rebound behavior (Fig. 3).

Impact velocities are defined as the velocity of the particle center directly before touching the liquid layer, while rebound velocity is defined right after rupture of the liquid bridge. To measure rotational velocities, the particles are marked by several dots before the experiments. Rotational velocity is calculated, by tracking these dots along with the particle center. For each configuration of collision parameters at least 15 experiments were conducted to get reliable results. Standard deviations are shown for each mean value.

During oblique collisions the normal impact velocity was kept constant at $1 \mathrm{~m} \mathrm{~s}^{-1}$ to achieve comparability. Thus, with increasing collision angle from the vertical direction the tangential impact velocity and accordingly the total impact velocity increase as well.

\subsubsection{Materials}

Glass beads (Swarco Type S) of two different sizes and $\gamma$ aluminum oxide spheres $\left(\gamma-\mathrm{Al}_{2} \mathrm{O}_{3}\right.$, company Sasol) were used as particles. Table 1 summarizes the properties of the particles. Both particles feature a high sphericity of above 0.91

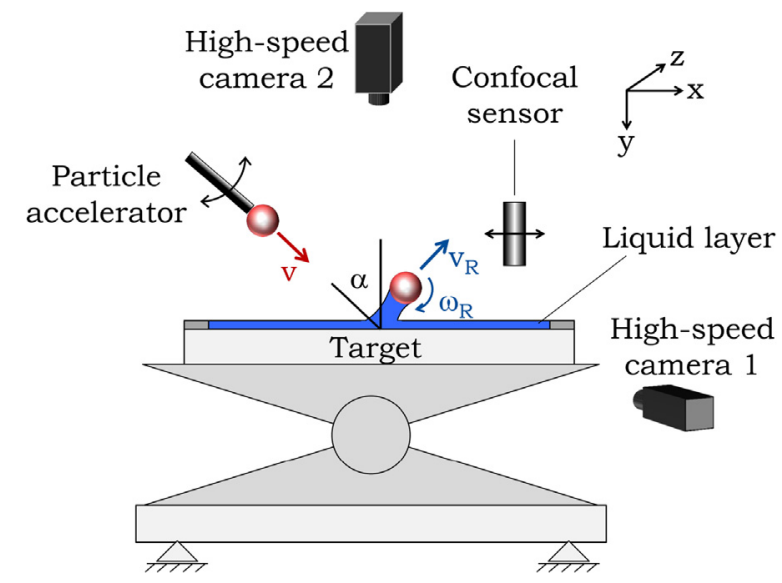

Fig. 3 - Schematic representation of the experimental setup for measuring the coefficient of restitution of a particle impacting obliquely on a target plate covered with a liquid layer.

and an average surface roughness in the range of a few micrometer. The target plate was also made of glass and was $80 \mathrm{~mm} \times 80 \mathrm{~mm} \times 10 \mathrm{~mm}(\mathrm{~W} \times \mathrm{L} \times \mathrm{H})$ in size. The thickness of the plate was proven to be large enough to neglect effects of elastic waves inside the material by equation 18 of Antonyuk et al. (2010).

Various Newtonian liquids were used for the layer on the wall: Water, glycerol-water solutions with different viscosities and a solution of a surfactant, in this case $60 \mathrm{gL}^{-1}$ Tween 20 water solution, with half the surface tension of water (Table 2). The concentration of the Tween 20 solution was chosen as critical micelle concentration as given in Helenius et al. (1979). Viscosity of each liquid used was measured in a RHEOTEST RN 4.1 (company RHEOTEST Medingen $\mathrm{GmbH}$ ). Surface tension of the Tween 20 solution was determined by Du-Noüy-method in a K100 Force Tensiometer (company Krüss GmbH).

\section{Results and discussion}

\subsection{Assumptions for capillary bridge geometry}

For calculation of the force balance of wet collisions the geometry of the capillary bridge is important. As discussed above, the shape of the bridge is assumed as toroid. In Fig. 4 the formation of a capillary bridge during rebound of a particle from a wet wall is shown exemplary for a glass particle. The assumption of a circular contour of the bridge is reasonable for nearly the complete lifetime of the bridge. To calculate the geometry two input parameters are required: the half-filling angle $\varphi$ 




$25 \%$

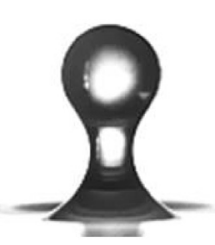

$50 \%$

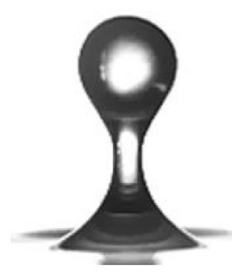

$75 \%$

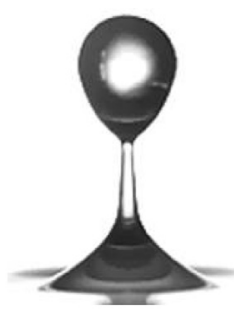

$100 \%$

Fig. 4 - Evolution of capillary bride shape during lifetime.

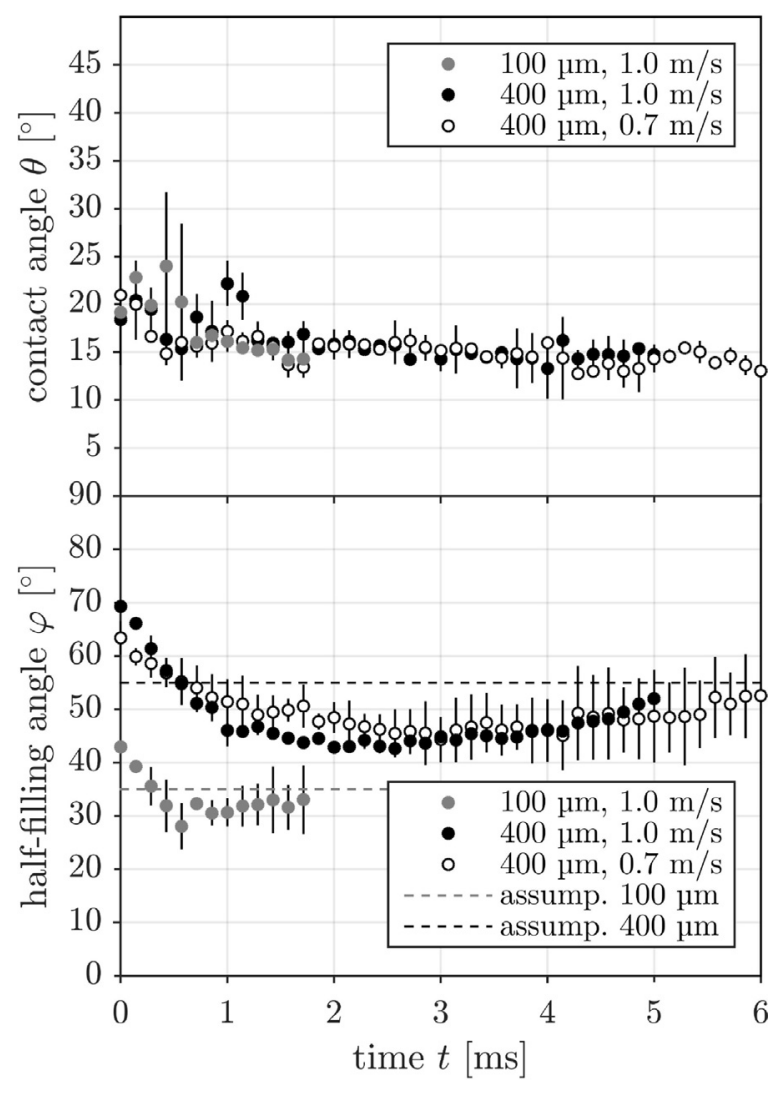

Fig. 5 - Half-filling angle and contact angle over bridge lifetime for glass particles impacting on a glass wall.

and the contact angle $\theta$, for which approximate values were determined from exemplary images of collision experiments.

Fig. 5 displays measured half-filling and contact angles over bridge lifetime. The contact angle is nearly constant over a large part of bridge lifetime, except for about the first millisecond, some scatter of the results is quite high. Furthermore, it does not change with variation of layer thickness or impact velocity. Hence, the contact angle was assumed constant in the force balance model. Measurements for glass particles as well as for $\gamma-\mathrm{Al}_{2} \mathrm{O}_{3}$ particles and various liquids resulted in a (dynamic) contact angle of approximately $15^{\circ}$ for both materials and all liquids, which was then assumed in the simulations.

The half-filling angle features a more complex trend with bridge lifetime. In the beginning, when the particle is still partially submerged in the liquid layer on the wall, the half-filling angle decreases. As soon as a liquid bridge is fully built, the half-filling angle is approximately constant over a long period of bridge lifetime. Only, when the shape of the liquid bridge constricts (right image in Fig. 4) the half-filling angle slightly increases again, while the upper part of the capillary bridge

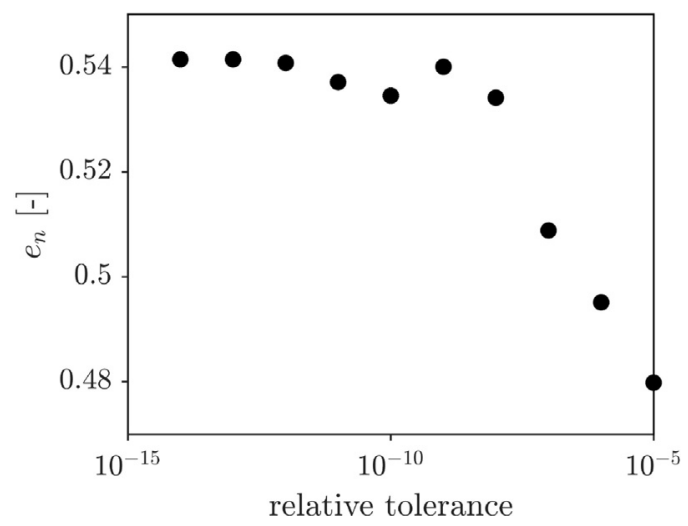

Fig. 6 - Study of convergence.

gains a droplet-like form. A decrease of the layer thickness results in an decrease of the half-filling angle, because the particle cannot penetrate as far into the thinner layer. Since the exact trend of half-filling angle with bridge lifetime varies with layer thickness and liquid viscosity and no models are present in literature to predict these dependencies, the half-filling angle is approximated by a constant average value for simplification. With increasing viscosity the average half-filling angle slightly decreased in the experiments by a few degrees. The values approximated for the model are summarized in Appendix A (Table 5).

\subsection{Convergence study}

Before using the force balance model the calculation has to be tested regarding numerical stability. As mentioned above, the force balance is solved in Matlab via function ode45, which sets the time step automatically, while keeping a relative and absolute tolerance for the results. Both relative and absolute tolerances have to be specified for the simulation. Fig. 6 shows the numerical results for a glass particle impacting with $1 \mathrm{~m} \mathrm{~s}^{-1}$ on a glass plate covered by a $400 \mu \mathrm{m}$ thick water layer for varying relative tolerance. The absolute tolerance was always three decimal powers smaller than the relative tolerance. Since the resulting coefficient of restitution is constant for relative tolerances smaller than $10^{-13}$, for all simulations the following tolerances are used: relative tolerance $10^{-13}$ and absolute tolerance $10^{-16}$.

\subsection{Normal collisions}

Using the particle and liquid properties as well as half-filling and contact angles as input parameters, rebound behavior can now be predicted via the force balance model. Fig. 7 shows a comparison between experiments of glass particles impacting on a glass plate and the proposed force balance 

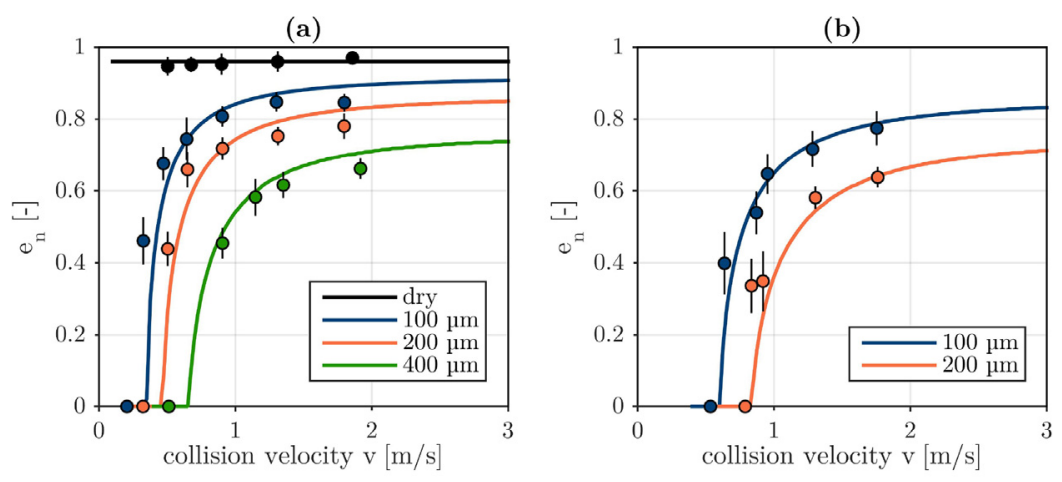

(c)
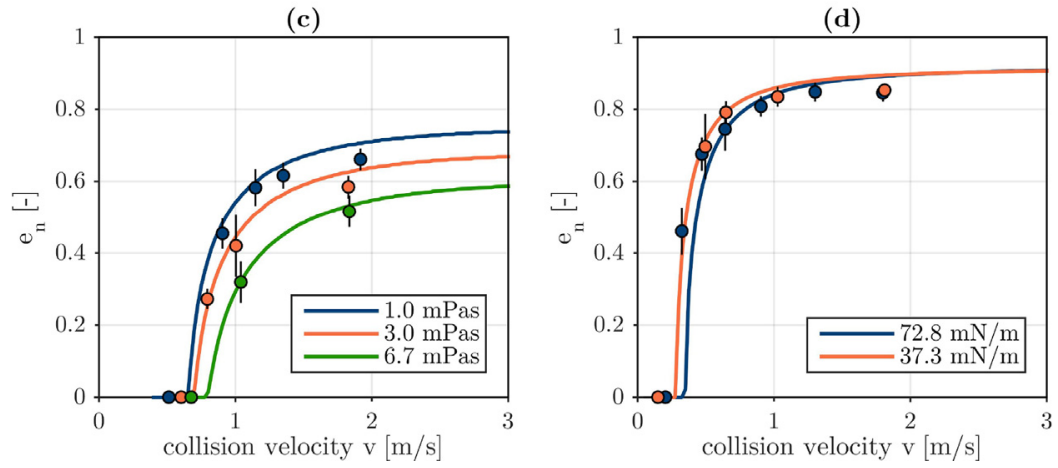

Fig. 7 - Validation of the normal CoR in dependence of collision velocity for $1.74 \mathrm{~mm}$ glass particles and different layer thickness of water (a), $0.91 \mathrm{~mm}$ glass particles and different layer thickness of water (b), $1.74 \mathrm{~mm}$ glass particles, $200 \mu \mathrm{m}$ layer thickness and varying viscosity (c) and $1.74 \mathrm{~mm}$ glass particle, $100 \mu \mathrm{m}$ layer thickness and varying surface tension (d). Solid line: force balance; circles: own experiments.

model. The constant behavior of the dry coefficient of restitution (Antonyuk et al., 2010) regarding collision velocity (black signs in (a)) are nicely represented by the model as could be assumed, since the coefficient of restitution is an input parameter of the dry contact model by Tsuji et al. (1992). Applying a liquid layer on the plate results experimentally in a strong dependence of the normal coefficient of restitution on the collision velocity as well as the layer thickness (Fig. 7(a)): Below a critical "sticking" velocity the normal coefficient of restitution is zero, because the rebound energy of the particle is too small to make the liquid bridge rupture. Above this sticking velocity, the normal coefficient of restitution is found to increase steeply first. When increasing the impact velocity further, the slope decreases until a constant value is reached asymptotically, which always stays smaller than the dry coefficient of restitution. This typical trend was also observed for example by Kantak et al. (2005), Gollwitzer et al. (2012), Müller et al. (2013) and Müller and Huang (2016). In accordance to previous experimental works (Antonyuk et al., 2009; Gollwitzer et al., 2012; Crüger et al., 2016a; Ma et al., 2016), an increase in layer thickness, leads to a decrease of the normal coefficient of restitution, because the particle penetrates deeper into the higher liquid layer, resulting in a longer time, the dissipative forces have time to act. The force balance model proposed in this work is able to represent these dependencies. In detail, the force balance nicely predicts the overall trends with increasing collision velocity as well as layer thickness. It however slightly overpredicts the coefficient of restitution for high velocities. These small differences might be further reduced by applying other viscous and capillary force models. The viscous force models in literature were developed for particles in an infinite fluid, however no models exist, which cover a particle partly submerged in a liquid layer. Thus, the existing models had to be adjusted to find an approximation for the real physics. Sim- ilarly, existing capillary models are for (quasi) static bridges. The bridge formation and elongation in the investigated case of an impacting and rebounding particle however is highly dynamic. Therefore, the small differences between model and experiment in this work might still be reducible by developing more appropriate models for capillary and viscous forces, which however is out of the scope of this work. Furthermore, the overall conformity is already assumed sufficiently high.

Fig. 7(b) displays the coefficient of restitution for smaller glass particles of $0.91 \mathrm{~mm}$ in diameter at two different layer thicknesses. The experiments with these smaller particles are even better predicted by the force balance model than the larger particles. Sticking velocities as well as the overall trends are well captured. Overall the normal CoR shows a similar trend for both particle sizes (comparing (a) and (b)), where the smaller particle size also features smaller normal CoR at the same layer thickness, as was also predicted by Gollwitzer et al. (2012). This results mainly, because at the same layer thickness a smaller particle submerges deeper into the liquid than a larger one. Comparing instead experiments with the same ratio of layer thickness to particle size $\left(\delta_{\mathrm{l}} / d_{\mathrm{P}}=\right.$ const., e.g. $400 \mu \mathrm{m} / 1.74 \mathrm{~mm}$ to $200 \mu \mathrm{m} / 0.91 \mathrm{~mm}$ ) the normal CoR is similar, but still slightly lower for the smaller particles, both experimentally as well as by force balance model.

The effect of higher viscosity on the coefficient of restitution (Fig. 7(c)) is also well represented by the force balance model. Increasing viscosity leads to a decrease of the normal CoR experimentally (compare e.g. Antonyuk et al. (2009), Ma et al. (2013)), which is qualitatively and quantitatively accounted for in the model by increasing viscous forces.

Fig. 7(d) features the coefficient of restitution for two different surface tensions. The experimental results show no considerable difference due to surface tension. The force balance model predicts slightly higher coefficients of restitution 
for smaller surface tension at collision velocities close to the sticking velocity. The influence however is small and is inside the standard deviations of the experiments. Therefore, good agreement can be concluded.

Fig. 8 summarizes results if instead of a glass particle a $\gamma-\mathrm{Al}_{2} \mathrm{O}_{3}$ particle is used. Also for $\gamma-\mathrm{Al}_{2} \mathrm{O}_{3}$ particles normally impacting on a glass plate the model gives a good prediction of the normal coefficient of restitution. Most predicted sticking velocities as well as dependencies regarding collision velocity and layer thickness fit the experimental results. Liquids with higher viscosity than water (Fig. 8(b)) can be predicted similarly well.

Fig. 9 displays the distribution of the mass-related total dissipated energy during a collision into fractions due to contact forces, gravitational, viscous and capillary forces for two particle sizes $\left(\delta_{1} / d_{\mathrm{P}}=\right.$ const. $)$ of glass and different collision velocities. Total dissipated energy increases with increasing collision velocity according to its relation to the coefficient of restitution (Eq. (1)). Overall, energy dissipation due to viscous and capillary forces is dominant, while contact forces and gravity feature a minor effect in energy dissipation. Dissipation due to gravitational and contact forces however cannot be neglected, especially at high collision velocities. At a closer look the fraction of dissipation via contact forces as well as viscous forces increase with increasing collision velocity, while energy dissipation owing to gravitational and capillary forces are nearly constant. Comparing different particle sizes, for smaller particles (Fig. 9(b)) the fraction of dissipated energy, which results from capillary forces, is considerably larger than for bigger particles (Fig. 9(a)). Thus, capillary forces increase with decreasing particle size, which in fact leads to the slightly smaller normal CoR for smaller particle diameters mentioned above.

Overall, the proposed force balance model appears to be suitable for predicting the normal coefficient of restitution for wet normal collisions of different materials and particle sizes in dependence of layer thickness, viscosity as well as surface tension.



(b)

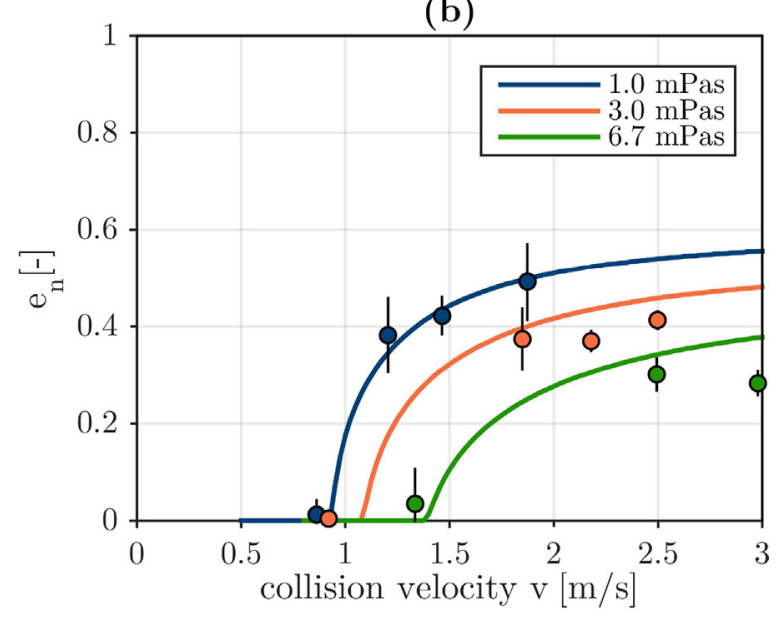

Fig. 8 - Validation of the normal CoR of $\gamma-\mathrm{Al}_{2} \mathrm{O}_{3}$ particles in dependence of collision velocity for different layer thickness of water (a) and viscosity at a layer thickness of $200 \mu \mathrm{m}$ (b). Solid line: force balance model; circles: experiments. (a)

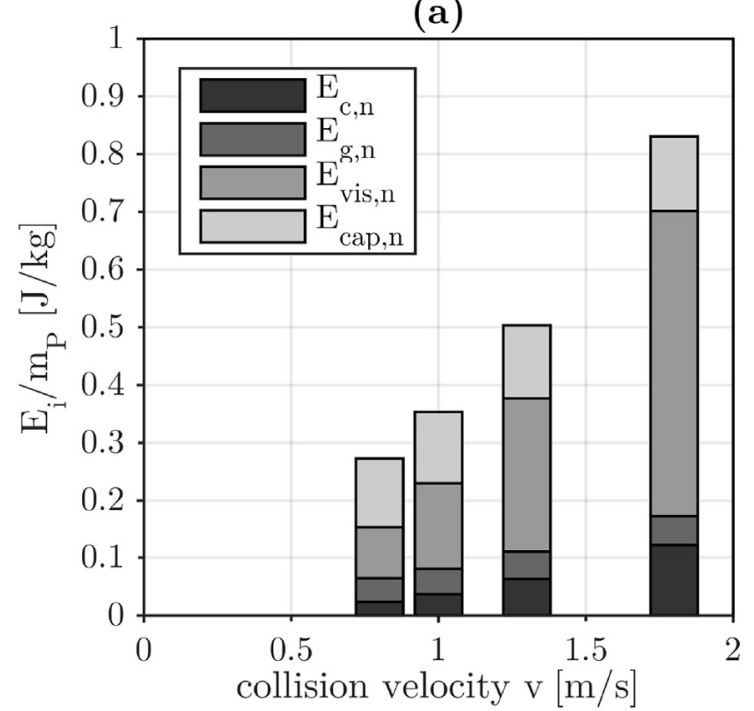

(b)

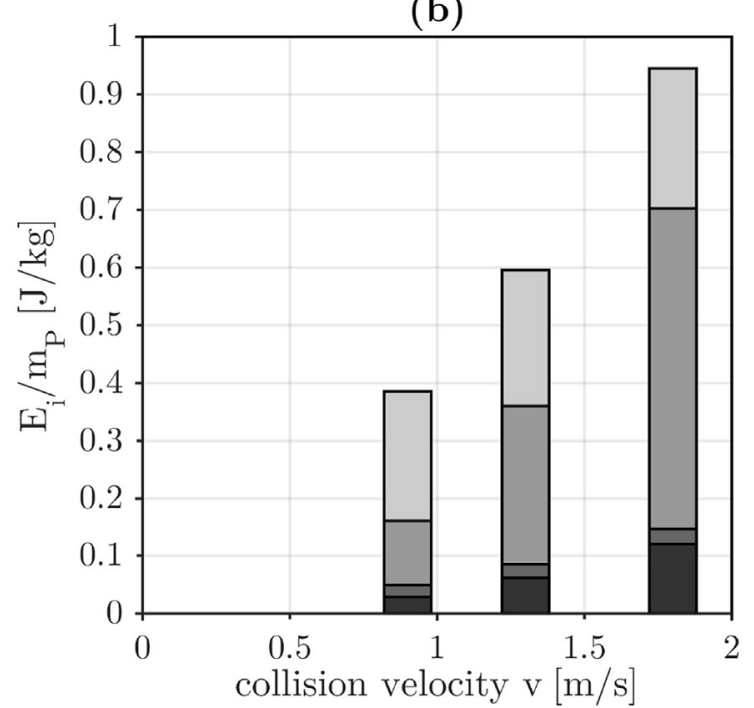

Fig. 9 - Dissipative energies due to contact forces, gravitational, viscous and capillary forces normalized by particle mass at different collision velocities for $1.74 \mathrm{~mm}$ glass particles and a $400 \mu \mathrm{m}$ water layer (a) compared to collisions of $0.91 \mathrm{~mm}$ glass particles and a $200 \mu \mathrm{m}$ water layer (b). 

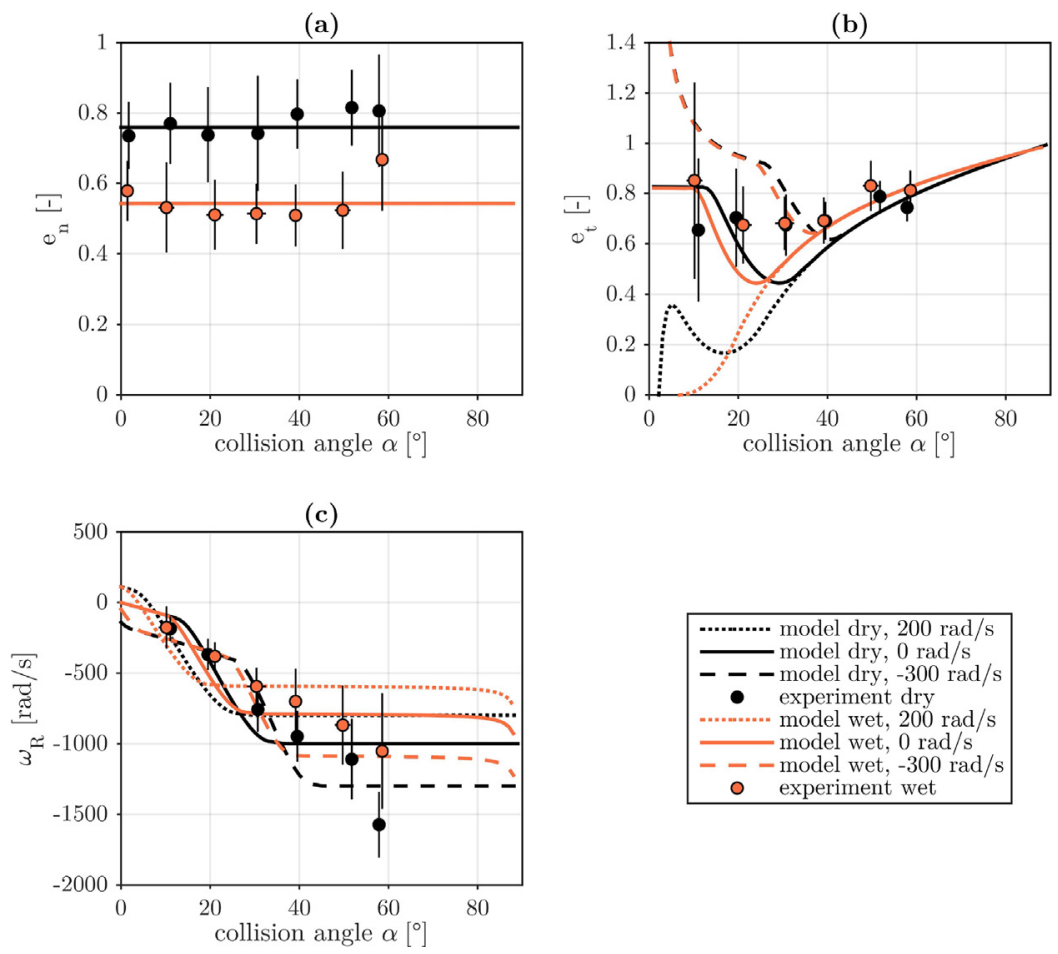

Fig. 10 - Comparison of experimental and model results of normal CoR (a), tangential CoR (b) and rotation velocity after rebound (c) of dry $\gamma-\mathrm{Al}_{2} \mathrm{O}_{3}$ particles obliquely impacting on a glass plate, which is either dry (black) or covered by a $100 \mu \mathrm{m}$ thick layer of Tween $\mathbf{2 0}$ (orange), in dependence of collision angle. (For interpretation of the references to color in this figure legend, the reader is referred to the web version of the article.)

Table 3 - Sliding friction coefficient $\mu_{\mathrm{sl}}$ used for the force balance of a $\gamma-\mathrm{Al}_{2} \mathrm{O}_{3}$ particle obliquely impacting a glass plate.

\begin{tabular}{lc} 
Layer & $\mu_{\text {sl }}[-]$ \\
\hline Dry & 0.195 \\
Tween 20 & 0.160 \\
35\% glycerol & 0.140 \\
\hline
\end{tabular}

\subsection{Oblique collision}

For oblique collisions the sliding friction coefficient $\mu_{\mathrm{sl}}$ acts as another input parameter. It was measured for dry $\gamma-\mathrm{Al}_{2} \mathrm{O}_{3}$ particles in a Schulze ring shear tester (ASTM, 2018) to be approximately 0.195. For example Joseph and Hunt (2004) as well as McFarlane and Tabor (1950) showed experimentally that friction is reduced if the colliding surfaces are wet, because the liquid acts as lubricant. Åhrström et al. (2003) found the friction coefficients to decrease further, when the liquid viscosity is increased. However, in literature no model exist, which predicts the influence of liquid layers on the friction coefficient between a particle and a wall quantitatively. Hence, the friction coefficients for wet collisions are fitted to the experimental results by slightly reducing the measured dry friction coefficient. The values used in this force balance are summarized in Table 3. As already mentioned, for all investigated configurations of oblique collisions a constant normal velocity of $1 \mathrm{~m} \mathrm{~s}^{-1}$ was used. Thus, with increasing collision angle the tangential velocity as well as total impact velocity increase.

Fig. 10 compares results of the force balance model and experiments of a $\gamma-\mathrm{Al}_{2} \mathrm{O}_{3}$ particle colliding obliquely with a dry or wet target. Since initial rotation of the particle varied between $180 \mathrm{rad} \mathrm{s}^{-1}$ and $-252 \mathrm{rad} \mathrm{s}^{-1}$ simulation results are shown for three cases of initial rotation: $200 \mathrm{rad} \mathrm{s}^{-1}, 0 \mathrm{rad} \mathrm{s}^{-1}$ and $-300 \mathrm{rad} \mathrm{s}^{-1}$. The normal coefficient of restitution shown in diagram (a) appears to be independent of collision angle and thus of tangential impact velocity both from the experiments as well as via the force balance model. The influence of the liquid layer on the normal CoR is also well predicted by the force balance model. Furthermore, the model indicates, that the normal CoR is independent of initial rotation, since all three simulations coincide in the same line. A more detailed look at the influence of initial particle rotation is taken later in Fig. 11. The independence of the normal coefficient of restitution regarding tangential impact velocity was also found by Antonyuk et al. (2010) for dry collisions and e.g. by Kantak and Davis (2004), Joseph and Hunt (2004) as well as Yang and Hunt (2006) for wet collisions with liquid layers or immersed in liquid, respectively.

The tangential coefficient of restitution is displayed in diagram (b) of Fig. 10. The force balance model predicts a strong dependence of the tangential CoR on collision angle as well as on initial rotation. In the model case without any initial rotation of the particle the tangential CoR is approximately constant at about 0.82 for small collision angles. With increasing collision angle it first decreases and after reaching a minimum increases until it reaches the value 1 at a collision angle of $90^{\circ}$. A collision at a collision angle of $90^{\circ}$ is a limiting case, where the particle only slides on the surface and no real contact happens. The position of the minimum is strongly dependent on the sliding friction coefficient (not directly shown in the diagram). Comparable minima are also found experimentally by Gorham and Kharaz (2000), Kharaz et al. (1999), Foerster et al. (1994) and Dong and Moys (2006) during dry collisions, as well as by several authors for wet collisions of rough surfaces (e.g. Joseph and Hunt (2004) and Yang and Hunt (2006)). This minimum is a result of changing contact 
(a)

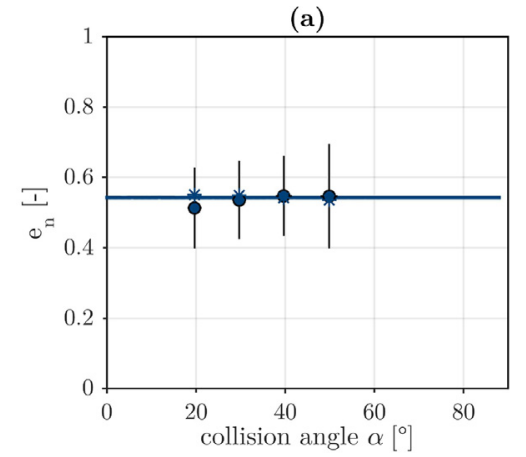

(c)

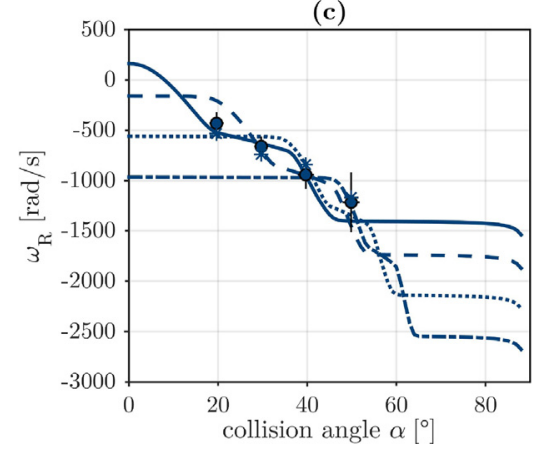

(b)

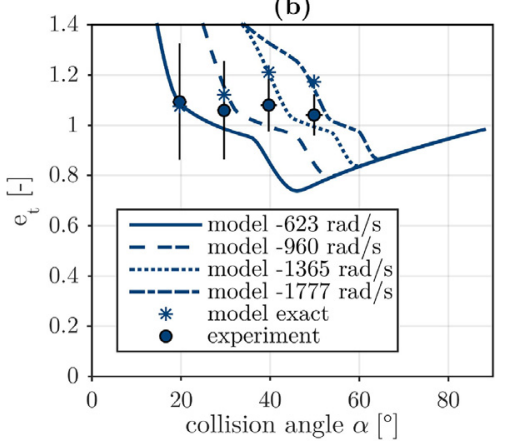

(d)

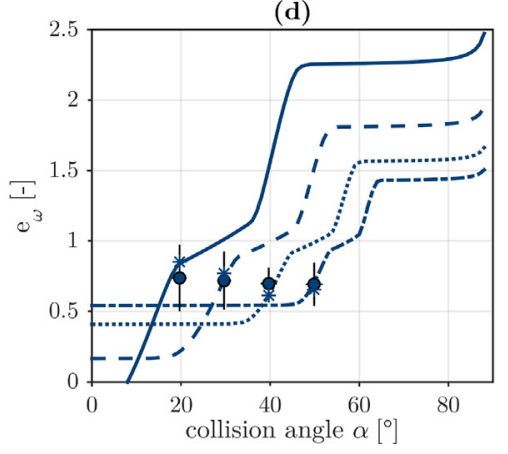

Fig. 11 - Influence of initial rotation on normal CoR (a), tangential CoR (b), rotational velocity after rebound (c) and rotational $\mathrm{CoR}$ (d) of $\gamma-\mathrm{Al}_{2} \mathrm{O}_{3}$ particles obliquely impacting on a glass plate covered by a $100 \mu \mathrm{m}$ thick layer of Tween 20 in dependence of collision angle.

motion between rolling/sticking and sliding contact (Foerster et al., 1994).

If a particle impacts with positive initial rotation (anticlockwise for a particle moving from left to right) the predicted tangential CoR is below zero for very small collision angles, which implies a change of direction for the tangential movement. The tangential CoR then increases with collision angle until the line coincides with that of the case without initial rotation at a specific collision angle. At this collision angle the particle fully slides on the wall surface. In dependence of the value of positive initial rotation the tangential coefficient of restitution might also run through a maximum and a minimum in dependence of collision angle. In this case a specific change between rolling and sliding of the particle on the wall takes place comparable to the minimum for collisions without initial rotation. Similar results were reported from experiments of Dong and Moys (2006), where the tangential coefficient also increased from negative values to nearly one for a steel ball impacting with negative initial rotation on a steel wall at collision angles ranging from $0^{\circ}$ to $60^{\circ}$. For a particle initially rotating in negative direction the tangential CoR decreases from values above one at small collision angles until it reaches a minimum. Also for positive rotation Dong and Moys (2006) found a similar trend for the tangential coefficient of restitution with collision angle as predicted by the force balance model. A tangential CoR larger than 1 means that after collision the particle has more kinetic energy in tangential direction than before the collision, because rotation is converted to tangential movement during the collision. At the collision angle with the minimum in tangential CoR the particle slides on the plate and the tangential coefficient of restitution is equal to that of the case without initial rotation. During the decrease of the tangential CoR with collision angle the slope changes strongly at certain collision angles. These turning points result when the particle partly rolls (sticks) and partly slides on the wall surface. Depending on the duration of rolling contact and sliding contact the slope changes. Application of a liquid layer leads to a slight decrease of the sliding friction coefficient (input parameter into model). Additionally, the liquid layer causes a viscous dissipation of energy directed against momentary tangential movement. Thus, in sum the values of tangential coefficient of restitution slightly shift to the left. At high collision angles the tangential CoR of a wet collision gets smaller than the dry one. This decrease results from an increase of viscous dissipation in tangential direction. With collision angles tending towards $90^{\circ}$ the tangential impact velocity tends to infinity $\left(v_{\mathrm{n}}=\right.$ const.) thus resulting in strongly increasing viscous forces in tangential direction. The experimental results fit quite nice into the model results. At low collision angles the experiments show large standard deviations, which however can be explained by the experimentally varying initial rotation: At small collision angles the force balance model reveals a high sensitivity of the tangential CoR regarding initial rotation, because rotational energy is in the same order of magnitude as kinetic energy in tangential direction. This sensitivity is represented in the experiments as standard deviation. The rotational velocity after the collision (Fig. 10(c)) is also strongly dependent on collision angles according to the force balance model. Except for positive initial collision velocities at small collision angles $\left(<10^{\circ}\right) \omega_{\mathrm{R}}$ is predicted negative. With increasing collision angle the absolute value of the post-collisional rotation increases until complete sliding occurs, which then results in a constant $\omega_{\mathrm{R}}$. The slope of the increase changes in dependence of the rolling-sliding regimes according to the tangential coefficient of restitution. This is reasonable, since in the force balance model tangential, translational movement and rotation are coupled in the velocity at the contact point. Different initial particle rotations have only small effect on post-rotation at small collision angles, e.g. only slightly shifting the otherwise similar trends. 
This shift ultimately leads to smaller absolute post-rotation for positive initial rotation and higher post-rotation for negative initial rotation compared to the case without any initial rotation. A liquid layer leads to smaller absolute rotational velocity due to a smaller sliding friction coefficient. Furthermore, the liquid layer results in an increase of the absolute rotation after rebound at high collision angles $\left(>80^{\circ}\right)$. As mentioned before, the tangential velocity approaches infinity at very high collision angles leading to high tangential forces inside the liquid layer and thus a momentum on the particle. This momentum increases strongly at large collision angles resulting in the detected increase of rotation after rebound. The tangential force during solid-solid contact is in these cases limited by Coulomb's friction and therefore constant. Comparing the model with experiments reasonable agreement is found. Small deviations (e.g. dry collision at $60^{\circ}$ ) between model and experiment might also result from inhomogeneities of the $\gamma-\mathrm{Al}_{2} \mathrm{O}_{3}$ particles (e.g. different roughness and therefore varying friction) and the experimental variations of the initial rotation. In literature sometimes a minimum or maximum, depending on definition of rotation direction, is reported for the post-rotation for dry collisions (Kharaz et al., 2001; Antonyuk et al., 2010), which is not found here in the simulation or in the experiments. However, the experiments from literature featuring an extrema in postcollisional rotation are always conducted with constant total impact velocity instead of constant normal velocity as in this work. Therefore, in those experiments the normal velocity and thus normal contact force and contact duration are reduced with increasing collision angle. Since during sliding tangential contact forces are defined by the normal contact force, postrotation decreases at large contact angles, where the contact is purely sliding. In this work the normal impact velocity is constant leading to a constant post-collisional rotation velocity. A rotational coefficient of restitution was not analyzed for these results, since for an initial rotation velocity of $0 \mathrm{rad} \mathrm{s}^{-1}$ it is not defined.

The influence of initial rotation on collision dynamics is further investigated in Fig. 11. The normal, tangential and rotational coefficients of restitution as well as the rotational velocity after the collision are displayed for four different initial rotation velocities ranging from about $-600 \mathrm{rad} \mathrm{s}^{-1}$ up to $-1800 \mathrm{rad} \mathrm{s}^{-1}$. All other parameters were kept the same. For each initial rotation velocity one validation experiment was conducted. With the described setup it was not possible to change the collision angle while keeping the rotational velocity constant, so no additional validation experiments were carried out.

Also for high initial rotation of the particle the normal CoR stays constant both in the model and in the experiments. This result confirms the assumption of possible superposition of normal and tangential movement in the contact point, which was also reported by some other researcher (Dong and Moys, 2006; Joseph and Hunt, 2004; Kantak and Davis, 2004).

The tangential CoR shows similar trends for all four initial rotation velocities. With increasing (negative) rotation velocity prior to the impact the trend mostly shifts to higher collision angles. The collision angle, where complete sliding occurs, also shifts to higher values, although at each critical sliding point the lines coincide into one. Hence, the critical collision angle, when sliding starts, depends on initial rotation velocity. However initial rotation has no effect on the tangential coefficient of restitution during complete sliding. The experiments agree well with the simulations. Simulations with the



(b)

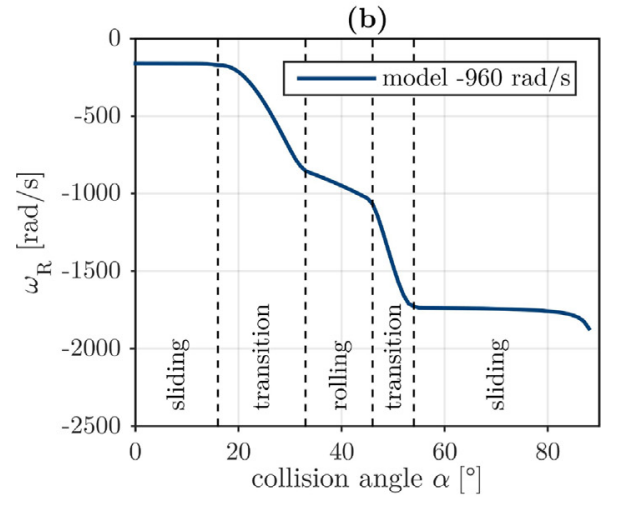

(c)

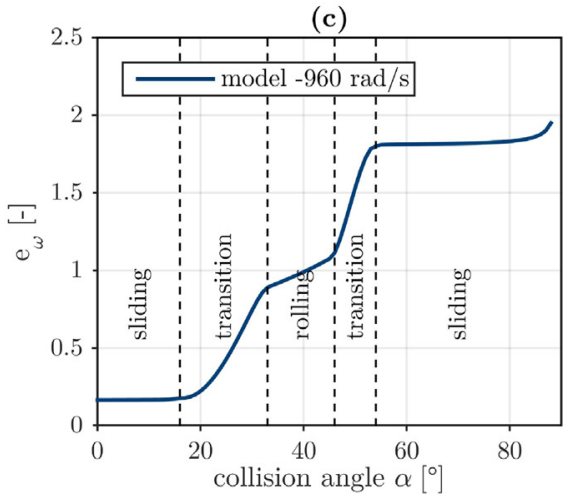

Fig. 12 - Rolling and sliding phases during oblique collision with initial rotation. (a) Tangential CoR; (b) rotation velocity after rebound; (c) rotational CoR.

exact input velocities, angles and rotational velocities of the experiments, shown as stars, are mostly close to the real experimental values and lie always at least inside the standard deviations. Especially for the two lower (absolute) initial rotation velocities the experimentally measured tangential coefficient of restitution is nearly exact the same as in the simulation.

Fig. 11(c) and (d) respectively show the rotational velocity after collision and the rotational coefficient of restitution $\left(e_{\omega}=\right.$ $\left.\frac{\omega_{\mathrm{R}}}{\omega}\right)$. Five different regimes can be detected for the rotational velocity: At low collision angles the rotation after rebound and the rotational CoR are constant. With increasing collision angle the absolute rotation velocity increases steeply, as does the rotational CoR (initial rotation is constant). At a specific collision angle, the slope gets smaller. Exactly in the middle of this third region (small slope of $\omega_{\mathrm{R}}$ ) the rotational coefficient of restitution reaches the value 1 and then increases above 1. Thus, rotational energy is gained. At even higher collision angles the slope increases again until at a critical 
(a)

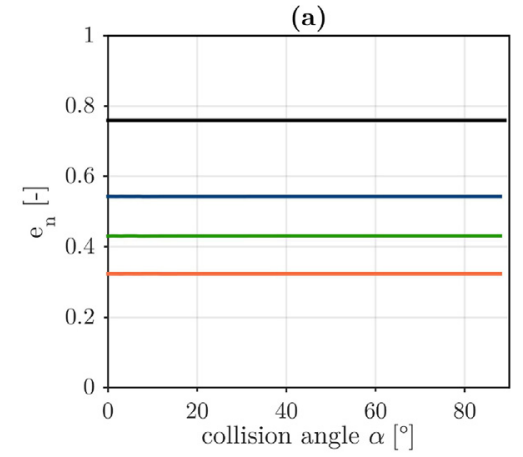

(c)

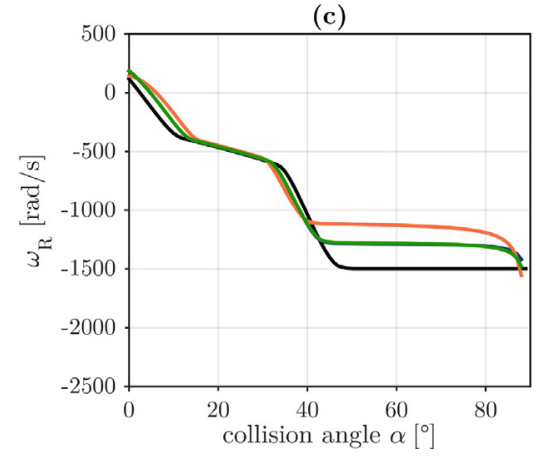

(b)

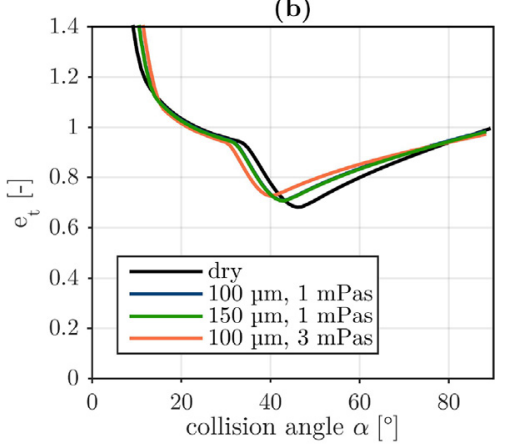

(d)

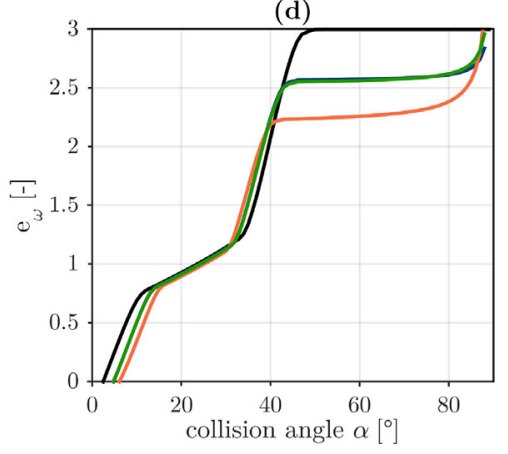

Fig. 13 - Influence of liquid properties on normal CoR (a), tangential CoR (b), rotational velocity after rebound (c) and rotational CoR (d) predicted by the force balance model for a $\gamma-\mathrm{Al}_{2} \mathrm{O}_{3}$ particle obliquely impacting on a glass plate with an initial particle rotation of $-500 \mathrm{rad} \mathrm{s}^{-1}$. (For interpretation of the references to color in the citation of this figure, the reader is referred to the web version of the article.)

collision angle the rotation velocity after collision as well as rotational CoR get constant again. With further increase of collision angle close to $90^{\circ}$ post-rotation is strongly enhanced due to increased viscous effects as mentioned before.

These five regimes, which are present for rotational velocity, tangential and rotational CoR (exemplary marked for an initial rotation velocity of $-960 \mathrm{rad} \mathrm{s}^{-1}$ in Fig. 12) can be explained by switching between rolling and sliding contacts. In the first regime (constant $\omega_{\mathrm{R}}$ ) initial rotation strongly dominates the velocity in the contact point $\left(v_{\mathrm{c}}=v_{\mathrm{t}}+\omega \cdot R_{\mathrm{P}}\right)$. As a result the tangential contact force is larger than $\mu_{\mathrm{sl}} \cdot F_{\mathrm{c}, \mathrm{n}}$ and the particle slides. Since the normal contact force is constant ( $v_{\mathrm{n}}=$ const.) the tangential contact force is constant as well is this case, leading to constant dissipation of rotational energy. Part of this energy is also converted to translational movement in tangential direction $\left(e_{t}>1\right)$. With increasing collision angle the translational tangential velocity $v_{\mathrm{t}}$ increases. In the investigated cases rotation is negative while translational movement in tangential direction is positive. Therefore, the velocity in the contact decreases with increasing collision angle. Thus, the tangential contact force decreases and at a specific collision angle the particle starts to roll on the wall surface. Here the second region starts, which is described by a transition, from the case, where the particle on a large part of the contact time slides and only a short time rolls, to the case, when the particle mostly rolls. The third regime starts, when rolling during the complete contact time is reached. Passing through this regime, the translational tangential velocity on a critical collision angle gets equal to $\omega \cdot R_{\mathrm{P}}$ resulting in a tangential contact force of zero. Therefore, no energy is converted between translational and rotational movement and both tangential CoR and rotational CoR are equal to the value 1 . Further increasing the collision angle $v_{t}$ gets larger than $\omega \cdot R_{P}$ and translational movement is converted to rotation during the contact, leading to a rotation CoR larger than one (and $e_{t}<1$ ). When the collision angle is large enough the particle again starts to partially slide on the wall resulting in a second transition regime until again complete sliding is reached with constant rotational velocity after rebound in the fifth regime. All validation experiments agree well with the model, although they only represent the first transition regime. Further validation might be beneficial for complete validation of the model.

To further discuss the influence of liquid properties on rebound behavior Fig. 13 shows results of the force balance model for a $\gamma-\mathrm{Al}_{2} \mathrm{O}_{3}$ particle initially rotating with $-500 \mathrm{rad} \mathrm{s}^{-1}$ impacting on a glass plate. In normal direction the liquid properties have a strong influence in the force balance model. Application of a liquid layer on the wall leads to a strong decrease of the normal CoR. An increase of the layer thickness (green) as well as an increase of the liquid viscosity (orange) reduces the normal $\mathrm{CoR}$ even further. These results were already discussed in detail for normal collisions. The tangential CoR as well as rotational velocity after rebound and rotational CoR however are only slightly influenced by the liquid. It was assumed, that a liquid layer would reduce the sliding friction coefficient. Thus, the transition between the different regimes of rolling and sliding is slightly shifted to smaller collision angles. An increase of viscosity was assumed to further reduce the sliding friction coefficient leading to another small shift of the collision angles, where transition between rolling and sliding happens. Ultimately, the influence of liquids, especially of the layer thickness, on tangential movement and rotation however is predicted to be very small.

Fig. 14 shows experimental results of the same system at comparable parameter configurations. The initial rotation used in these experiments is summarized in Table 4. As was predicted by the force balance model the normal coefficient of 

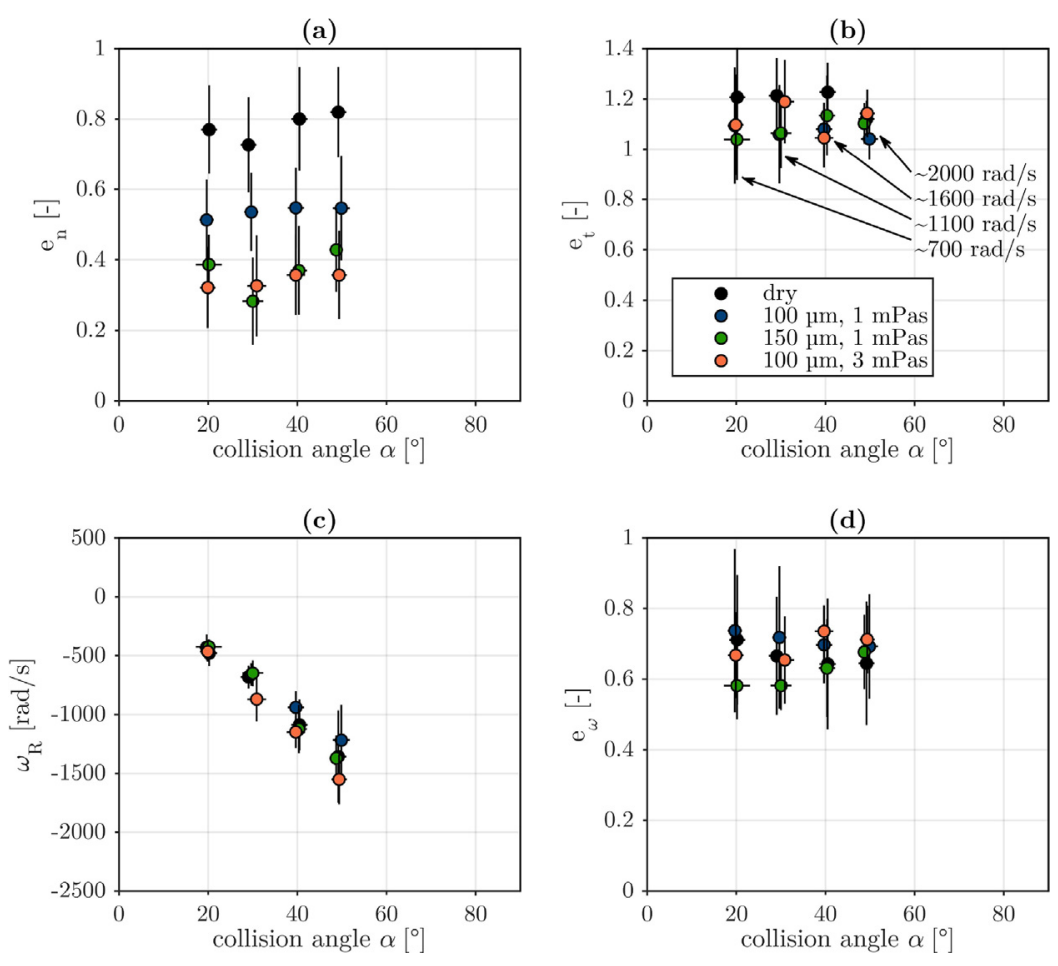

Fig. 14 - Influence of liquid properties on normal CoR (a), tangential CoR (b), rotational velocity after rebound (c) and rotational CoR (d) experimentally found for a $\gamma-\mathrm{Al}_{2} \mathrm{O}_{3}$ particle obliquely impacting on a glass plate with comparable initial particle rotation (summarized in Table 4).

Table 4 - Initial rotation during experiments in Figs. 11 and 14.

\begin{tabular}{cllll} 
& \multicolumn{1}{c}{ Dry } & \multicolumn{2}{c}{ Tween 20 } & $\begin{array}{c}50 \% \text { glycerol } \\
\eta_{1}=3 \mathrm{mPa} \mathrm{s}\end{array}$ \\
\cline { 2 - 4 } & - & \multicolumn{2}{c}{$\eta_{1}=1 \mathrm{mPas}$} & $\delta_{1}=100 \mu \mathrm{m}$ \\
\hline $20^{\circ}$ & $-698 \pm 172$ & $-623 \pm 188$ & $-741 \pm 102$ & $-704 \pm 96$ \\
$30^{\circ}$ & $-1056 \pm 179$ & $-961 \pm 199$ & $-1125 \pm 178$ & $-1330 \pm 109$ \\
$40^{\circ}$ & $-1777 \pm 411$ & $-1366 \pm 196$ & $-1803 \pm 172$ & $-1564 \pm 135$ \\
$50^{\circ}$ & $-2171 \pm 569$ & $-1777 \pm 344$ & $-2035 \pm 152$ & $-2181 \pm 151$ \\
\hline
\end{tabular}

restitution is strongly influenced by the properties of the liquid layer, while the values of tangential CoR, rotation velocity after rebound and rotational coefficient of restitution show no considerable influence. Variations between the experimental results all lie within each standard deviation. Similar results were also reported by Kantak and Davis (2004), who found the normal coefficient of restitution to be strongly dependent on liquid properties, while tangential coefficient of restitution and rotation are only marginally influenced by thin liquid layers. Consequently, the force balance model can be concluded to predict the (mostly small) influence of liquid layers on oblique collision dynamics reasonably well.

\section{Conclusion}

In this work we propose a force balance model, which predicts the rebound characteristics of particles normally and obliquely colliding with a dry or wet wall. Normal, tangential and rotational velocities are taken into account and analyzed via coefficients of restitution. The model is compared to extensive experimental research and the model was found to predict the experimental results well. The major findings and limitations are summarized in the following:
1. The properties of the liquid layer feature a strong influence on the normal coefficient of restitution but are nearly negligible regarding tangential coefficient of restitution and rotation for thin liquid layers in the investigated range of parameters.

2. For oblique collisions normal and tangential forces and velocities can be superimposed. The normal coefficient of restitution is independent of collision angle and initial rotation of the particle. Tangential coefficient of restitution as well as rotational coefficient of restitution are strongly dependent on both collision angle and initial rotation.

3. A clear transition between rolling and sliding regimes can be distinguished in the tangential and rotational CoR. To validate the complete dependence some further experiments might be beneficial. Nevertheless all experiments so far are well predicted by the model.

4. The proposed force balance model is able to fully predict the rebound behavior of wet particle-wall collisions. It however strongly depends on precise knowledge of the material parameters and geometry of the liquid bridge, especially half-filling angle and sliding friction coefficient.

Next, the model should to be extended and validated for particle-particle collision, where slight modification to the model might be necessary (e.g. assumptions for the capillary force). Furthermore, the third dimension should be included. Ultimately, this model, especially the influence of liquids, could be included into a DEM code to be able to simulate not only two-body contacts, but also larger processes.

\section{Acknowledgements}

We gratefully acknowledge for the financial support: German Research Foundation (DFG), Germany, and NWO domain 
Applied and Engineering Sciences TTW, The Netherlands. Project number HE 4526/9-2.

\section{Appendix A. Liquid volume}

For calculating the liquid bridge volume the geometrics of a toroid approximation are used and can be expressed in four fractions shown in Fig. 15: a cylindrical approximation of the bridge $V_{b, 1}$, minus the rotational volume of the fraction of the toroid section $\mathrm{V}_{\mathrm{b}, 2}$, rotational volume of the triangle $\mathrm{V}_{\mathrm{b}, 3}$ and the volume section of the particle immersed in liquid $V_{b, 4}$ :

$\mathrm{V}_{\mathrm{b}}=\mathrm{V}_{\mathrm{b}, 1}-\mathrm{V}_{\mathrm{b}, 2}-\mathrm{V}_{\mathrm{b}, 3}-\mathrm{V}_{\mathrm{b}, 4}$

Approximating the contact angle between liquid layer and liquid bridge to be zero $\mathrm{V}_{\mathrm{b}, 1}$ is calculated by the maximal radius of the bridge $\left(r_{\mathrm{a}}+r_{\mathrm{m}}\right)$ and the total height of the bridge:

$\mathrm{V}_{b, 1}=\pi\left(r_{a}+r_{m}\right)^{2} \cdot\left(y-R_{P} \cdot \cos \varphi-\delta_{l}\right)$

The volume of a body of rotation is calculated by a product of the cross-sectional area, which is rotated, and the perimeter of the rotation, which results in the following expressions for $\mathrm{V}_{\mathrm{b}, 2}$ and $\mathrm{V}_{\mathrm{b}, 3}$ :

$$
\begin{gathered}
\mathrm{V}_{\mathrm{b}, 2}=\frac{1}{2} r_{\mathrm{m}}^{2}(\pi-(\theta+\phi)) \cdot 2 \pi \\
{\left[r_{\mathrm{a}}+r_{\mathrm{m}}-\frac{4 r_{\mathrm{m}} \sin \frac{\pi-(\theta+\varphi)}{2}}{3(\pi-(\theta+\varphi))} \cdot \sin \left(\frac{\pi-(\theta+\varphi)}{2}\right)\right]} \\
\mathrm{V}_{\mathrm{b}, 3}=\frac{1}{2} r_{\mathrm{m}}^{2} \sin (\theta+\varphi) \cdot \cos (\theta+\varphi) \cdot 2 \pi\left[r_{\mathrm{c}}+\frac{2}{3} r_{\mathrm{m}} \sin (\theta+\varphi)\right]
\end{gathered}
$$

The volume of the spherical cap of the particle is calculated via

$$
\mathrm{V}_{\mathrm{b}, 4}=\frac{1}{3} \pi\left(R_{\mathrm{P}}(1-\cos \varphi)\right)^{2} \cdot\left(3 R_{\mathrm{P}}-R_{\mathrm{P}}(1-\cos \varphi)\right)
$$

\section{Appendix B. Half-filling angle}

\begin{tabular}{llll}
$\begin{array}{l}\text { Table } \mathbf{5} \text { - Half-filling angle used in the force balance } \\
\text { model for different experimental configurations. }\end{array}$ \\
\hline Particle & Liquid & $\delta_{1}[\mu \mathrm{m}]$ & $\varphi\left[^{\circ}\right]$ \\
\hline $1.8 \mathrm{~mm}$ glass & Water & 100 & 35 \\
& & 200 & 45 \\
& & 400 & 55 \\
& $35 \%$ glycerol & 400 & 53 \\
& $50 \%$ glycerol & 400 & 51 \\
& Tween 20 & 100 & 35 \\
& & 100 & 45 \\
& Water & 200 & 55 \\
& & 100 & 28 \\
$\mathrm{Al}_{2} \mathrm{O}_{3}$ mm glass & Water & 200 & 45 \\
& & 400 & 53 \\
& & 100 & 34 \\
& $35 \%$ glycerol & 200 & 44 \\
& & 200 & 43 \\
& $50 \%$ glycerol & 100 & 35 \\
& Tween 20 & 150 & 42 \\
\hline
\end{tabular}

\section{References}

Åhrström, B.-O., Penchinat, C., Norrby, T., 2003. An experimental study of the influence of heat storage and transportability of different lubricants on friction under transient

elastohydrodynamic conditions. Proc. Institut. Mech. Eng. J: J. Eng. Tribol. 217 (1), 27-37,

http://dx.doi.org/10.1243/135065003321164785.

Antonyuk, S., Heinrich, S., Deen, N., Kuipers, H., 2009. Influence of liquid layers on energy absorption during particle impact. Particuology 7 (4), 245-259,

http://dx.doi.org/10.1016/j.partic.2009.04.006.

Antonyuk, S., Heinrich, S., Tomas, J., Deen, N.G., van Buijtenen, M.S., Kuipers, J.A.M., 2010. Energy absorption during compression and impact of dry elastic-plastic spherical granules. Granular Matter 12 (1), 15-47,

http://dx.doi.org/10.1007/s10035-009-0161-3.

American Society for Testing and Materials, 2018. ASTM D 6773 16: Standard Test Method for Bulk Solids Using Schulze Ring
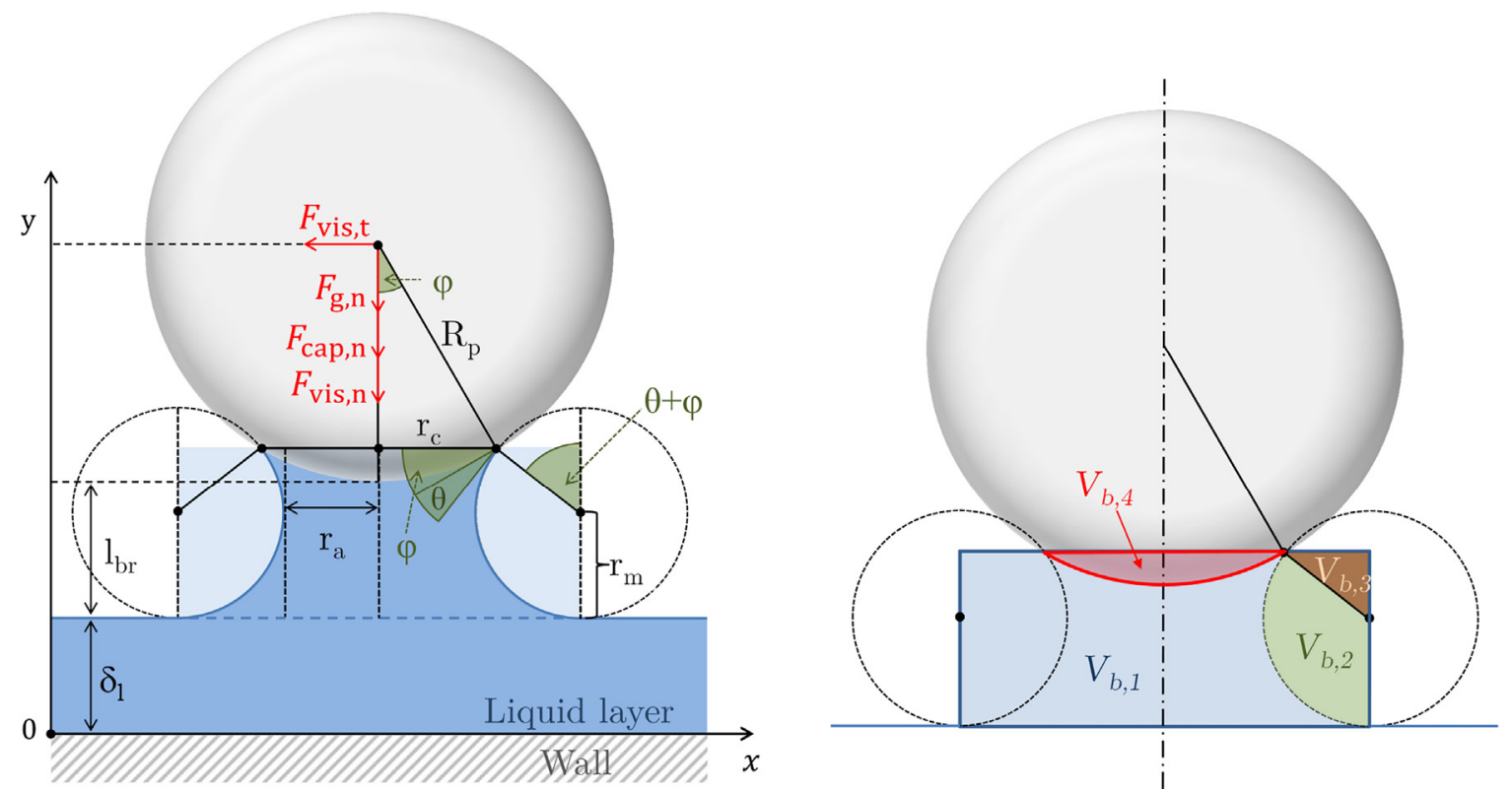

Fig. 15 - Geometrics and schematic of volume fractions used for calculation of liquid bridge volume. 
Shear Tester. ASTM International, West Conshohocken, PA, http://dx.doi.org/10.1520/D6773-16.

Barnocky, G., Davis, R.H., 1988. Elastohydrodynamic collision and rebound of spheres: experimental verification. Phys. Fluids 31 (6), 1324-1329, http://dx.doi.org/10.1063/1.866725.

Brilliantov, N.V., Spahn, F., Hertzsch, J.-M., Pöschel, T., 1996. Model for collisions in granular gases. Phys. Rev. E 53, 5382-5392, http://dx.doi.org/10.1103/PhysRevE.53.5382.

Buck, B., Tang, Y., Heinrich, S., Deen, N.G., Kuipers, J., 2017. Collision dynamics of wet solids: Rebound and rotation. Powder Technol. 316, 218-224,

http://dx.doi.org/10.1016/j.powtec.2016.12.088, fluidization for Emerging Green Technologies.

Chan, D.Y.C., Horn, R.G., 1985. The drainage of thin liquid films between solid surfaces. J. Chem. Phys. 83 (10), 5311-5324, http://dx.doi.org/10.1063/1.449693.

Crüger, B., Salikov, V., Heinrich, S., Antonyuk, S., Sutkar, V., Deen, N., Kuipers, J.A.M., 2016a. Coefficient of restitution for particles impacting on wet surfaces: an improved experimental approach. Particuology 25, 1-9, http://dx.doi.org/10.1016/j.partic.2015.04.002.

Crüger, B., Heinrich, S., Antonyuk, S., Deen, N.G., Kuipers, J.A.M., 2016b. Experimental study of oblique impact of particles on wet surfaces. Chem. Eng. Res. Des. 110, 209-219, http://dx.doi.org/10.1016/j.cherd.2016.01.024.

Darabi, P., Pougatch, K., Salcudean, M., Grecov, D., 2009. A novel coalescence model for binary collision of identical wet particles. Chem. Eng. Sci. 64 (8), 1868-1876, http://dx.doi.org/10.1016/j.ces.2009.01.017.

Davis, R.H., Serayssol, J.-M., Hinch, E.J., 1986. The elastohydrodynamic collision of two spheres. J. Fluid Mech. 163, 479-497, http://dx.doi.org/10.1017/S0022112086002392.

Davis, R.H., Rager, D.A., Good, B.T., 2002. Elastohydrodynamic rebound of spheres from coated surfaces. J. Fluid Mech. 468, 107-119, http://dx.doi.org/10.1017/S0022112002001489.

Di Renzo, A., Di Maio, F.P., 2004. Comparison of contact-force models for the simulation of collisions in DEM-based granular flow codes. Chem. Eng. Sci. 59 (3), 525-541, http://dx.doi.org/10.1016/j.ces.2003.09.037.

Dong, H., Moys, M.H., 2006. Experimental study of oblique impacts with initial spin. Powder Technol. 161 (1), 22-31, http://dx.doi.org/10.1016/j.powtec.2005.05.046.

Ennis, B.J., Tardos, G., Pfeffer, R., 1991. A microlevel-based characterization of granulation phenomena. Powder Technol. 65 (1), 257-272, http://dx.doi.org/10.1016/0032-5910(91)80189-P.

Feng, X.-Q., Li, H., Zhao, H.-P., Yu, S.-W., 2009. Numerical simulations of the normal impact of adhesive microparticles with a rigid substrate. Powder Technol. 189 (1), 34-41, http://dx.doi.org/10.1016/j.powtec.2008.05.014.

Foerster, S.F., Louge, M.Y., Chang, H., Allia, K., 1994.

Measurements of the collision properties of small spheres. Phys. Fluids 6 (3), 1108-1115, http://dx.doi.org/10.1063/1.868282.

Fu, J., Adams, M.J., Reynolds, G.K., Salman, A.D., Hounslow, M.J., 2004. Impact deformation and rebound of wet granules. Powder Technol. 140 (3), 248-257, http://dx.doi.org/10.1016/j.powtec.2004.01.012.

Glycerine Producers' Association, 1963. Physical Properties of Glycerine and its Solutions. Glycerine Producers' Association.

Goldman, A., Cox, R., Brenner, H., 1967. Slow viscous motion of a sphere parallel to a plane wall - I motion through a quiescent fluid. Chem. Eng. Sci. 22 (4), 637-651,

http://dx.doi.org/10.1016/0009-2509(67)80047-2.

Gollwitzer, F., Rehberg, I., Kruelle, C.A., Huang, K., 2012. Coefficient of restitution for wet particles. Phys. Rev. E 86, 011303, http://dx.doi.org/10.1103/PhysRevE.86.011303.

Gorham, D.A., Kharaz, A.H., 2000. The measurement of particle rebound characteristics. Powder Technol. 112 (3), 193-202, http://dx.doi.org/10.1016/S0032-5910(00)00293-X.

Helenius, A., McCaslin, D.R., Fries, E., Tanford, C., 1979. Properties of detergents. In: Biomembranes Part G: Bioenergetics: Biogenesis of Mitochondria, Organization, and Transport, vol.
56 of Methods in Enzymology. Academic Press, pp. 734-749, http://dx.doi.org/10.1016/0076-6879(79)56066-2.

Hertz, H., 1882. Über die Berührung fester elastischer Körper. Journal für die reine und angewandte Mathematik 92, 156-171.

Hogekamp, S., Stang, M., Schubert, H., 1994. Jet agglomeration and dynamic adhesion forces. Chem. Eng. Process.: Process Intensification 33 (5), 313-318, http://dx.doi.org/10.1016/0255-2701(94)02001-9.

Jain, D., Deen, N.G., Kuipers, J.A.M., Antonyuk, S., Heinrich, S., 2012. Direct numerical simulation of particle impact on thin liquid films using a combined volume of fluid and immersed boundary method. Chem. Eng. Sci. 69 (1), 530-540, http://dx.doi.org/10.1016/j.ces.2011.11.018.

Joseph, G.G., Hunt, M.L., 2004. Oblique particle-wall collisions in a liquid. J. Fluid Mech. 510, 71-93, http://dx.doi.org/10.1017/S002211200400919X

Joseph, G.G., Zenit, R., Hunt, M.L., Rosenwinkel, A.M., 2001. Particle-wall collisions in a viscous fluid. J. Fluid Mech. 433, 329-346, http://dx.doi.org/10.1017/S0022112001003470.

Kan, H., Nakamura, H., Watano, S., 2015. Numerical simulation of particle-particle adhesion by dynamic liquid bridge. Chem. Eng. Sci. 138, 607-615, http://dx.doi.org/10.1016/j.ces.2015.08.043.

Kan, H., Nakamura, H., Watano, S., 2016. Effect of particle wettability on particle-particle adhesion of colliding particles through droplet. Powder Technol. 302, 406-413, http://dx.doi.org/10.1016/j.powtec.2016.08.066.

Kantak, A.A., Davis, R.H., 2004. Oblique collisions and rebound of spheres from a wetted surface. J. Fluid Mech. 509, 63-81, http://dx.doi.org/10.1017/S0022112004008900.

Kantak, A.A., Galvin, J.E., Wildemuth, D.J., Davis, R.H., 2005. Low-velocity collisions of particles with a dry or wet wall. Micrograv. - Sci. Technol. 17 (1), 18-25, http://dx.doi.org/10.1007/BF02870971.

Kharaz, A.H., Gorham, D.A., Salman, A.D., 1999. Accurate measurement of particle impact parameters. Meas. Sci. Technol. 10 (1), 31.

Kharaz, A.H., Gorham, D.A., Salman, A.D., 2001. An experimental study of the elastic rebound of spheres. Powder Technol. 120 (3), 281-291, http://dx.doi.org/10.1016/S0032-5910(01)00283-2.

Kralchevsky, P.A., Nagayama, K., 2001. Capillary bridges and capillary-bridge forces. In: Kralchevsky, P.A., Nagayama, K. (Eds.), Particles at Fluids Interfaces and Membranes Attachment of Colloid Particles and Proteins to Interfaces and Formation of Two-Dimensional Arrays, vol. 10 of Studies in Interface Science. Elsevier, pp. 469-502, http://dx.doi.org/10.1016/S1383-7303(01)80052-1, Chapter 11

Kruggel-Emden, H., Simsek, E., Rickelt, S., Wirtz, S., Scherer, V., 2007. Review and extension of normal force models for the discrete element method. Powder Technol. 171 (3), 157-173, http://dx.doi.org/10.1016/j.powtec.2006.10.004.

Lian, G., Xu, Y., Huang, W., Adams, M.J., 2001. On the squeeze flow of a power-law fluid between rigid spheres. J. Non-Newtonian Fluid Mech. 100 (1-3), 151-164, http://dx.doi.org/10.1016/S0377-0257(01)00140-9.

Lin, S.-Y., Lin, J.-F., 2013. Numerical investigation of lubrication force on a spherical particle moving to a plane wall at finite Reynolds numbers. Int. J. Multiphase Flow 53, 40-53, http://dx.doi.org/10.1016/j.ijmultiphaseflow.2013.01.006.

Liu, G., Li, S., Yao, Q., 2011. A JKR-based dynamic model for the impact of micro-particle with a flat surface. Powder Technol. 207 (1-3), 215-223, http://dx.doi.org/10.1016/j.powtec.2010.11.002.

Luding, S., 1998. Collisions and contacts between two particles. In: Herrmann, H.J., Hovi, J.-P., Luding, S. (Eds.), Physics of Dry Granular Media. Springer Netherlands, Dordrecht, pp. 285-304, http://dx.doi.org/10.1007/978-94-017-2653-5_20.

Müller, T., Gollwitzer, F., Krülle, C.A., Rehberg, I., Huang, K., 2013. Scaling of the normal coefficient of restitution for wet impacts. AIP Conf. Proc. 1542 (1), 787-790, http://dx.doi.org/10.1063/1.4812049. 
Müller, T., Huang, K., 2016. Influence of the liquid film thickness on the coefficient of restitution for wet particles. Phys. Rev. E 93, 042904, http://dx.doi.org/10.1103/PhysRevE.93.042904.

Ma, J., Liu, D., Chen, X., 2013. Experimental study of oblique impact between dry spheres and liquid layers. Phys. Rev. E 88, 033018, http://dx.doi.org/10.1103/PhysRevE.88.033018.

Ma, J., Liu, D., Chen, X., 2015. Rotational behavior of dry spheres obliquely impacting on liquid layers. Powder Technol. 270 (Part B), 418-423, http://dx.doi.org/10.1016/j.powtec.2014.08.042.

Ma, J., Liu, D., Chen, X., 2016. Normal and oblique impacts between smooth spheres and liquid layers: liquid bridge and restitution coefficient. Powder Technol. 301, 747-759, http://dx.doi.org/10.1016/j.powtec.2016.07.001.

Matthewson, M.J., 1988. Adhesion of spheres by thin liquid films. Philos. Mag. A 57 (2), 207-216, http://dx.doi.org/10.1080/01418618808204510.

McFarlane, J.S., Tabor, D., 1950. Relation between friction and adhesion. Proc. R. Soc. Lond. A: Math. Phys. Eng. Sci. 202 (1069), 244-253.

Mikami, T., Kamiya, H., Horio, M., 1998. Numerical simulation of cohesive powder behavior in a fluidized bed. Chem. Eng. Sci. 53 (10), 1927-1940, http://dx.doi.org/10.1016/S0009-2509(97)00325-4.

Mindlin, R.D., Deresiewicz, H., 1953. Elastic spheres in contact under varying oblique forces. J. Appl. Mech. 20, 327-344.

Nase, S.T., Vargas, W.L., Abatan, A.A., McCarthy, J., 2001. Discrete characterization tools for cohesive granular material. Powder Technol. 116 (2-3), 214-223, http://dx.doi.org/10.1016/S0032-5910(00)00398-3.

Pitois, O., Moucheront, P., Chateau, X., 2000. Liquid bridge between two moving spheres: an experimental study of viscosity effects. J. Colloid Interface Sci. 231 (1), 26-31, http://dx.doi.org/10.1006/jcis.2000.7096.

Pitois, O., Moucheront, P., Chateau, X., 2001. Rupture energy of a pendular liquid bridge. Eur. Phys. J. B: Condens. Matter Complex Syst. 23 (1), 79-86, http://dx.doi.org/10.1007/s100510170084.

Shi, D., McCarthy, J., 2008. Numerical simulation of liquid transfer between particles. Powder Technol. 184 (1), 64-75, http://dx.doi.org/10.1016/j.powtec.2007.08.011.

Sutkar, V.S., Deen, N.G., Padding, J.T., Kuipers, J.A.M., Salikov, V., Crüger, B., Antonyuk, S., Heinrich, S., 2015. A novel approach to determine wet restitution coefficients through a unified correlation and energy analysis. AIChE J. 61 (3), 769-779, http://dx.doi.org/10.1002/aic.14693.
SWARCO-Vestglas Vetische Strahl- und Reflexglas GmbH, Technische Produktinformation Mahlperlen Type S, 2018a.

SWARCO-Vestglas Vetische Strahl- und Reflexglas GmbH ceroglass, Type S Glass Beads, 2018b, https://www.swarco.com/ ceroglass/Products/Wet-Grinding-Milling-Beads/Type-S-Glass-Beads.

Tang, Y., Kuipers, J.A.M., Buck, B., Heinrich, S., Deen, N.G., 2017. Interface-resolved simulations of normal collisions of spheres on a wet surface. AIChE J. 63 (11), 4774-4787.

Thornton, C., Cummins, S.J., Cleary, P.W., 2013. An investigation of the comparative behaviour of alternative contact force models during inelastic collisions. Powder Technol. 233, 30-46, http://dx.doi.org/10.1016/j.powtec.2012.08.012.

Thornton, C., 2009. A note on the effect of initial particle spin on the rebound behaviour of oblique particle impacts. Powder Technol. 192 (2), 152-156, http://dx.doi.org/10.1016/j.powtec.2008.12.015.

Tsuji, Y., Tanaka, T., Ishida, T., 1992. Lagrangian numerical simulation of plug flow of cohesionless particles in a horizontal pipe. Powder Technol. 71 (3), 239-250, http://dx.doi.org/10.1016/0032-5910(92)88030-L.

White, F.M., 2006. Viscous Fluid Flow, 3rd edition. McGraw-Hill.

Wu, C.-y., Li, L.-y., Thornton, C., 2003a. Rebound behaviour of spheres for plastic impacts. Int. J. Impact Eng. 28 (9), 929-946, http://dx.doi.org/10.1016/S0734-743X(03)00014-9.

Wu, C.-Y., Thornton, C., Li, L.-Y., 2003b. Coefficients of restitution for elastoplastic oblique impacts. Adv. Powder Technol. 14 (4), 435-448, http://dx.doi.org/10.1163/156855203769710663.

Wu, C.-Y., Thornton, C., Li, L.-Y., 2009. A semi-analytical model for oblique impacts of elastoplastic spheres. Proc. R. Soc. Lond. A: Math. Phys. Eng. Sci. 465 (2103), 937-960, http://dx.doi.org/10.1098/rspa.2008.0221.

Wu, M., Radl, S., Khinast, J.G., 2016. A model to predict liquid bridge formation between wet particles based on direct numerical simulations. AIChE J. 62 (6), 1877-1897, http://dx.doi.org/10.1002/aic.15184.

Wu, M., Khinast, J.G., Radl, S., 2017. Liquid transport rates during binary collisions of unequally-sized particles. Powder Technol. 309, 95-109, http://dx.doi.org/10.1016/j.powtec.2016.12.080.

Yang, F.-L., Hunt, M.L., 2006. Dynamics of particle-particle collisions in a viscous liquid. Phys. Fluids 18 (12), 121506, http://dx.doi.org/10.1063/1.2396925.

Zheng, Q., Zhu, H., Yu, A., 2012. Finite element analysis of the contact forces between a viscoelastic sphere and rigid plane. Powder Technol. 226, 130-142, http://dx.doi.org/10.1016/j.powtec.2012.04.032. 